Article

\title{
Intercellular Transfer of Oncogenic KRAS via Tunneling Nanotubes Introduces Intracellular Mutational Heterogeneity in Colon Cancer Cells
}

\author{
Snider Desir ${ }^{1,2}$, Phillip Wong ${ }^{1,3}$, Thomas Turbyville ${ }^{4}$, De Chen ${ }^{4}$, Mihir Shetty ${ }^{5}$, \\ Christopher Clark ${ }^{5}$, Edward Zhai ${ }^{1}$, Yevgeniy Romin ${ }^{6}$, Katia Manova-Todorova ${ }^{6}$, \\ Timothy K. Starr ${ }^{5}$ (D), Dwight V. Nissley ${ }^{4}$, Clifford J. Steer ${ }^{3}$, Subbaya Subramanian ${ }^{7}$ (D) and \\ Emil Lou 1,*(D)
}

1 Department of Medicine, Division of Hematology, Oncology and Transplantation, University of Minnesota, Minneapolis, MN 55455, USA

2 Department of Integrative Biology and Physiology, University of Minnesota, Minneapolis, MN 55455, USA

3 Department of Medicine, Division of Gastroenterology, Hepatology and Nutrition, University of Minnesota, Minneapolis, MN 55455, USA

4 NCI RAS Initiative, Cancer Research Technology Program, Frederick National Laboratory for Cancer Research, Frederick, MD 21702, USA

5 Department of Obstetrics and Gynecology, Division of Gynecologic Oncology, University of Minnesota, Minneapolis, MN 55455, USA

6 Molecular Cytology Core Facility, Memorial Sloan-Kettering Cancer Center, New York, NY 10065, USA

7 Department of Surgery, University of Minnesota, Minneapolis, MN 55455, USA

* Correspondence: emil-lou@umn.edu; Tel.: +1-612-624-5944

Received: 16 May 2019; Accepted: 18 June 2019; Published: 26 June 2019

check for updates

\begin{abstract}
Mutated forms of the RAS oncogene drive 30\% of all cancers, but they cannot be targeted therapeutically using currently available drugs. The molecular and cellular mechanisms that create a heterogenous tumor environment harboring both mutant and wild-type RAS have not been elucidated. In this study, we examined horizontal transfer of mutant KRAS between colorectal cancer (CRC) cells via a direct form of cell-to-cell communication called tunneling nanotubes (TNTs). TNT formation was significantly higher in CRC cell lines expressing mutant KRAS than CRC cell lines expressing wild-type RAS; this effect was most pronounced in metastatic CRC cell lines with both mutant KRAS and deficiency in mismatch repair proteins. Using inverted and confocal fluorescence time-lapse and fluorescence recovery after photobleaching (FRAP)-based microscopy, we observed GFP-tagged mutant KRAS ${ }^{\mathrm{G} 12 \mathrm{D}}$ protein trafficking between CRC cells through TNTs within a span of seconds to several minutes. Notably, acquisition of mutant KRAS increased Extracellular Signal-regulated Kinase (ERK) phosphorylation and upregulated tunneling nanotube formation in recipient wildtype CRC cells. In conclusion, these findings suggest that intercellular horizontal transfer of RAS can occur by TNTs. We propose that intercellular transfer of mutant RAS can potentially induce intratumoral heterogeneity and result in a more invasive phenotype in recipient cells.
\end{abstract}

Keywords: tunneling nanotubes; intercellular communication; KRAS; oncogene; cellular reprogramming; intercellular transfer; colon cancer; colorectal cancer; confocal microscopy

\section{Introduction}

RAS is a ubiquitous oncogene in cancers and is highly active and prevalent in both pancreatic (90-95\% KRAS mutations) and colorectal cancers (CRC) (35-40\%). KRAS acts as a critical driving force in these cancers, as mutated forms of KRAS are constitutively activated, permitting significant 
downstream effects including increased cell proliferation, tumor progression, and higher rates of metastasis [1-6]. There is also increasing evidence that mutated versions of KRAS lead to the development of chemoresistance and that subclones of mutated KRAS are present at the time of diagnosis of CRC even in tumors that are initially identified as wild-type (wt) for KRAS [7].

It has been shown that mutant KRAS subclones that arise early in tumorigenesis confer selective growth advantages for tumors as a whole, including drug resistance [8]. Furthermore, the proportion of mutant KRAS subclones can vary widely between tumors, and the spatial distribution of these subclones is associated with the most invasive regions of CRC tumors [8]. The current paradigm of emergence of KRAS-driven tumors relies on the premise that: (i) mutant KRAS arises in the setting of several potential risk factors, including aging and tobacco use; and (ii) cells that acquire mutant KRAS do so only in a replicative state from parent cells (i.e., vertical transmission). Horizontal transmission, however, provides an additional means by which cells within a defined tumor can share mutant molecular signals [9-11]. RAS itself has been shown to be transferred between cells via exosomes, propagating long-range cellular communication via a diffusible mechanism [12-14]. Further, intercellular transfer of the oncogenic $\mathrm{H}$-Ras subclass has been shown to occur between $\mathrm{B}$ and $\mathrm{T}$ cell lymphocytes, providing additional insight into the role of intercellular communication on antigen-presenting cells in general and also potential implications of transfer of RAS specifically $[15,16]$. Intratumoral heterogeneity of $K R A S$, in which multiple alleles of the oncogene exist within an individual tumor, can lead to the misdiagnosis of tumors as wild-type RAS. Such tumors, when treated with monoclonal antibody targeting the epidermal growth factor receptor (EGFR), will eventually develop resistance to anti-EGFR therapy, a characteristic most prominent in colorectal cancer $[17,18]$. We hypothesized that tunneling nanotubes (TNTs) provide an additional mechanism of intercellular communication of oncogenic KRAS among colon cancer cells. Intercellular transfer mediated by TNTs presents a new paradigm in which mutant oncogenic proteins, such as RAS, can be directly transmitted horizontally from cell to cell within tumors, thus inducing a greater state of intracellular and also intratumoral heterogeneity.

TNTs are ultrafine, long, filamentous actin-based protrusions of the cell plasma membrane. Characteristic morphologic properties include: (i) their non-adherence to the substratum when observed in in vitro cell culture; (ii) a relatively narrow diameter compared with other actin-based cell protrusions (50-800 nm); and (iii) lengths that can exceed 10-fold the diameter of TNT-forming cells $[9,19,20]$. TNTs have been shown to mediate intercellular redistribution and sharing of proteins, genetic materials including microRNAs and siRNAs, and other cytoplasmic cargo between cells $[10,11,21,22]$. We have also previously shown that tumor-derived exosomes can induce cells to upregulate formation of TNTs and utilize them as direct intercellular means for transport [23]. TNTs have been imaged in human and mouse model tumors extensively by our group and others using confocal fluorescence and other forms of high-resolution microscopy $[10,11,24]$. We recently reported the presence of TNTs connecting cells in tumor tissues obtained from colon cancer patients, in addition to other invasive malignancies [25]. Here we show that TNTs mediate intercellular transfer of mutant KRAS in recipient colon cancer cells, thus facilitating intracellular and molecular heterogeneity in the tumor microenvironment.

\section{Results}

\subsection{Increased TNT Formation in CRC Cells Harboring Mutant KRAS and Deficient Mismatch Repair}

We have previously found that the rate of TNT formation is heterogeneous and variable even among cancer types of similar tissue of origin. For this study, we hypothesized that colon carcinoma cells form TNTs at rates that vary based on KRAS status (wild type vs. mutant) and site of origin (i.e., cells derived from a primary CRC tumor vs. metastatic CRC tumors) (Table 1). 
Table 1. Clinical, molecular, and genetic characteristics of cell lines used in this study.

\begin{tabular}{|c|c|c|c|c|c|c|c|c|c|}
\hline $\begin{array}{l}\text { Cell Line } \\
\text { Number }\end{array}$ & Cell Line & $\begin{array}{c}\text { Primary Tissue of } \\
\text { Origin }\end{array}$ & Metastasis & $\begin{array}{l}\text { KRAS Wt or } \\
\text { Mutant }\end{array}$ & $\begin{array}{c}\text { Microsatellite } \\
\text { Status }\end{array}$ & $\begin{array}{l}\text { BRAF Wt or } \\
\text { Mutant }\end{array}$ & CMS Group & CIMP Status & References \\
\hline 1 & LOVO & Colon & $\begin{array}{c}\text { Left } \\
\text { supraclavicular } \\
\text { region }\end{array}$ & p.G13D & $\begin{array}{l}\text { Unstable } \\
\text { (MSI-H) }\end{array}$ & WT & CMS1 & CIMP-negative & {$[26-28]$} \\
\hline 2 & HCT-116 & Ascending colon & $\mathrm{n} / \mathrm{a}$ & p.G13D & $\begin{array}{l}\text { Unstable } \\
\text { (MSI-H) }\end{array}$ & WT & CMS4 & CIMP-positive & {$[26-28]$} \\
\hline 3 & SW480 & Descending colon & $\mathrm{n} / \mathrm{a}$ & p.G12V & Stable & WT & CMS4 & CIMP-negative & [27-29] \\
\hline 4 & HCT-8 & $\begin{array}{c}\text { Small intestine } \\
\text { (ileocecal)/colorectal }\end{array}$ & $\mathrm{n} / \mathrm{a}$ & WT & $\begin{array}{l}\text { Unstable } \\
\text { (MSI-H) }\end{array}$ & WT & CMS4 & unknown & {$[30]$} \\
\hline 5 & HT-29 & Colon & $\mathrm{n} / \mathrm{a}$ & WT & Stable & p.V600E & CMS3 & CIMP-positive & {$[26,27]$} \\
\hline 6 & AAC1 & Colon & $\mathrm{n} / \mathrm{a}$ & WT & Stable & WT & n/a (adenoma) & $\mathrm{n} / \mathrm{a}$ & [31] \\
\hline
\end{tabular}

$\mathrm{wt}=$ wild-type; CMS = Consensus Molecular Subtype; CIMP = CpG Island Methylator Phenotype; MSI-H = Microsatellite Instability-High status. Additional pertinent references: [27,28,32]. 
We examined TNT formation among five colorectal cancer cell lines and in a colon adenoma cell line (AAC1). The metastatic cell line LOVO and primary colon tumor-derived cell line HCT-116 both endogenously harbor mutant $K R A S^{\mathrm{G} 13 \mathrm{D}}$; both of these cell lines also are characterized by deficiencies in mismatch repair protein (dMMR), a genetic feature associated with microsatellite instability [30,33,34]. Cell line SW480 harbors mutant KRAS ${ }^{\mathrm{G} 12 \mathrm{~V}}$ variant; and cell lines HCT-8, HT-29, and AAC1 are KRAS wild-type (wt) [29,35,36]. HCT-8 also has dMMR. Further details are provided in Table 1.

We cultured cell lines in sub-confluent conditions for optimal TNT formation (Figure 1A,B) and quantified the number of TNTs and number of cells per high-power field at 24, 48, and 72-hour intervals (Figure 1C-E).

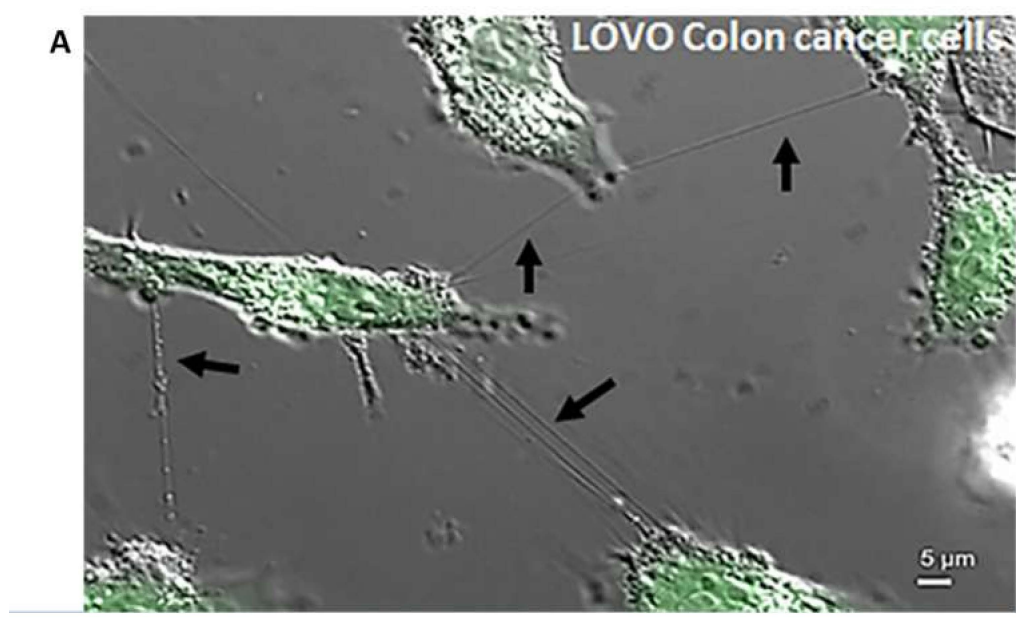

B
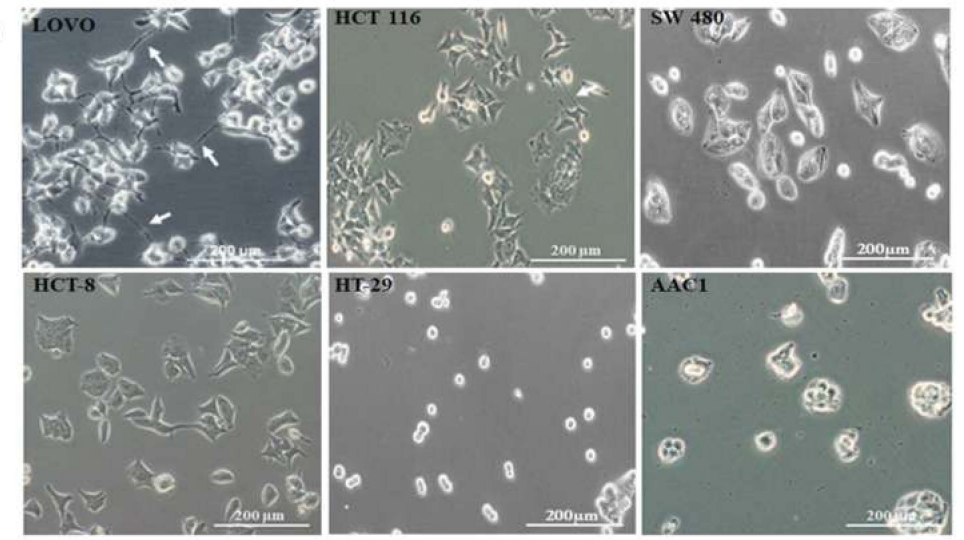

C
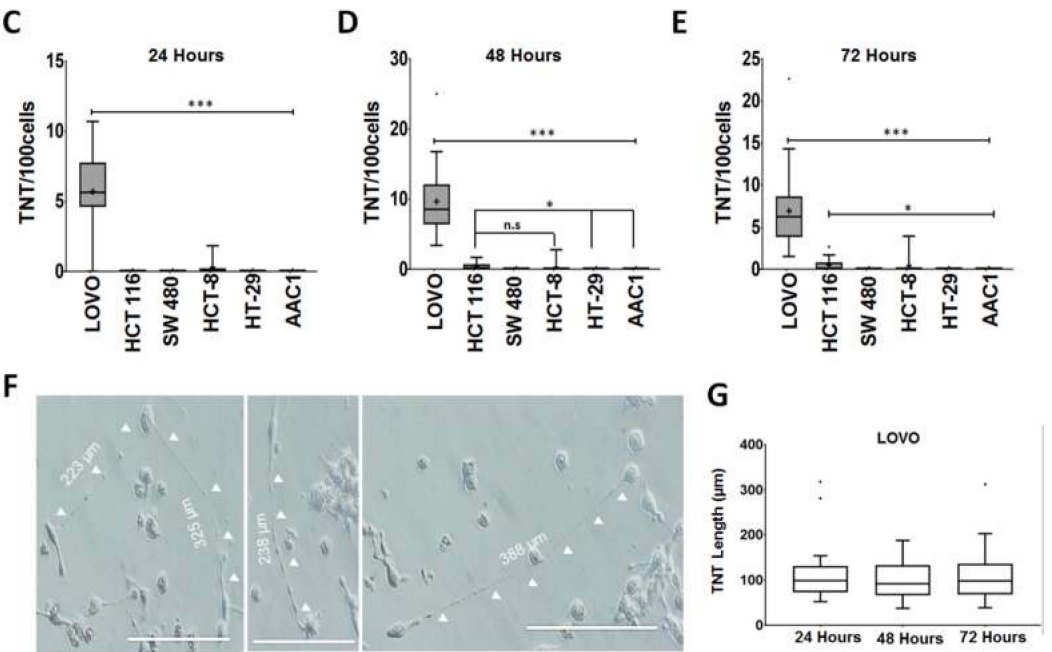
Figure 1. Differential rate of TNT formation among colorectal cancer cells. (A) TNTs form to connect colorectal cancer cells in vitro, particularly with invasive cell lines such as LOVO. As shown, TNTs can connect two or more cells to each other, and multiple TNTs can form between the same two cells. Scale bar $=5 \mu \mathrm{m}$. (B) Representative phase contrast microscopy images of each human colorectal cancer cell line used to quantitatively analyze changes in TNT formation over time (LOVO, HCT 116, SW480, HCT-8, and HT-29 and the premalignant adenoma cell line AAC1). Boxplot representation of TNTs per 100 cells over (B) $24 \mathrm{~h},($ C) $48 \mathrm{~h}$, and (D) $72 \mathrm{~h}$. Median values for each cell line were compared because of the non-normal distribution of TNT formation. TNTs were manually counted for each cell line over three days using an Olympus IX70 inverted microscope with a $20 \times$ objective lens. 10 fields of views were selected at random in triplicate experiments. (E) Phase contrast microscopy images of unusually long TNTs forming between LOVO cells. TNT length was estimated by using Image J to measure image pixels. (F) Box plot distribution of LOVO lengths over three days in culture. Symbols on the boxplot are as follows: Box, 1st to 3rd (Q1-Q3) Quartiles; + = Mean; Line inside box = Median. Asterisk symbol indicate statistical differences in median value; $\mathrm{n} . \mathrm{s}=$ non statistically significant. Scale bar $=200 \mu \mathrm{m}$.

Among the CRC cells tested, LOVO and HCT-116 cells formed the most TNTs (Figure 1). Metastatic LOVO cells formed markedly more TNTs than HCT-116 cells during the entire $72 \mathrm{~h}$ period. TNT formation was not evident among SW480, HT-29, or AAC1 cells. Interestingly, LOVO cells did not have the highest proliferation rate (Figure S1A), a characteristic we observed in other cancer lines that form a high number of TNTs [1-3]. In addition, the average length of TNTs that formed between LOVO cells did not differ significantly during the $72 \mathrm{~h}$ period, with a mean value of $100 \mu \mathrm{m}$ (Figure 1F-G; additional representative images in Figure S1B). Overall, these findings suggest that there is significant heterogeneity of TNT formation among CRC cell types, with the metastatic LOVO cell line exhibiting the highest rate of TNT formation.

\subsection{TNTs Facilitate Direct Intercellular Transfer of Oncogenic KRAS between CRC Cells}

It is well established that the emergence and expansion of mutant KRAS subclones can lead to intratumoral heterogeneity and treatment resistance. Several studies have suggested that mutant KRAS can transfer from cell-to-cell $[12,15,16,37]$, but it is unclear whether TNTs have a functional role in the trafficking of mutant KRAS.

To examine whether TNTs redistribute mutant KRAS, we co-cultured LOVO cells exogenously expressing green fluorescent protein (GFP)-tagged mutant KRAS construct along with HCT-8 cells labeled with CellTracker Red. Using fluorescence microscopy, we confirmed TNT formation and intercellular transport of GFP-tagged mutant KRAS within these TNTs (Figure 2A). We next employed fluorescence recovery after photobleaching (FRAP) to quantitate recovery of mutant KRAS trafficking within these TNTs (Figure 2B; Video S1).

The recovery time was rapid (within 30-40 s post-photobleaching). However, the extent of this recovery was not $100 \%$. This lack of complete recovery is consistent with other studies using FRAP $[15,38,39]$ and may be due at least in part to an immobile fraction. These data suggest that TNTs are open conduits allowing for transfer of mutant KRAS into the recipient cell. In a separate experiment, we further analyzed trafficking of mutant KRAS into recipient HCT-8 cells; we performed fluorescence microscopy and FRAP with photobleaching focused on the point of contact of a TNT with the recipient plasma membrane (Figure 2C, Video S2). Quantitative analysis of GFP recovery was again similar to the above experiment (Figure 2D). To ensure that cell trafficking and morphologic cellular changes associated with TNTs were, in fact, due to mutant KRAS expression and not attributable to GFP, we examined cells transfected with GFP alone as a negative control and found no changes in cell morphology (Figure S2 upper left panel) This was compared to cells transfected with GFP-tagged mutant KRAS (Figure S2 upper right panel) in which there were clear alterations in cell size and development of cell protrusions consistent with TNTs. Additional representative images of GFP-tagged mutant KRAS following transfection and protein expression are provided in Figure S2. 
A
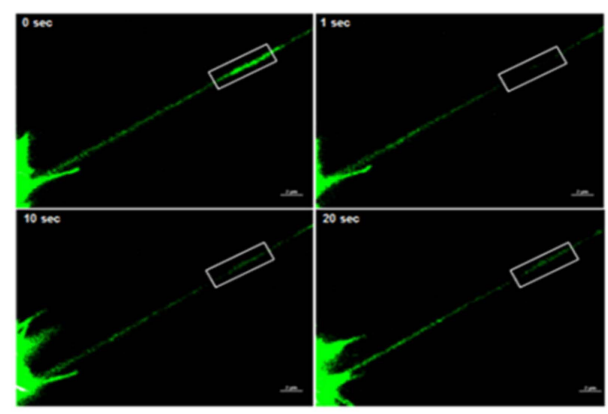

C

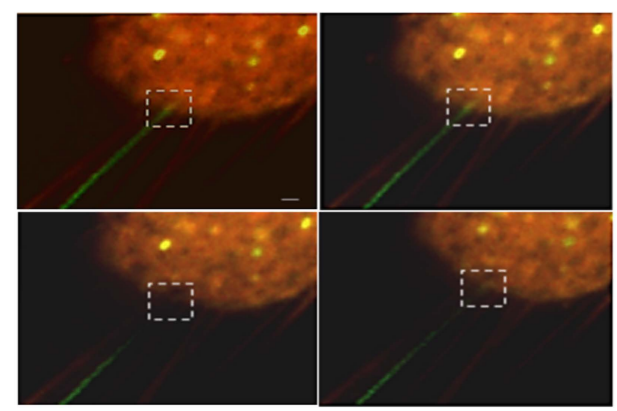

B

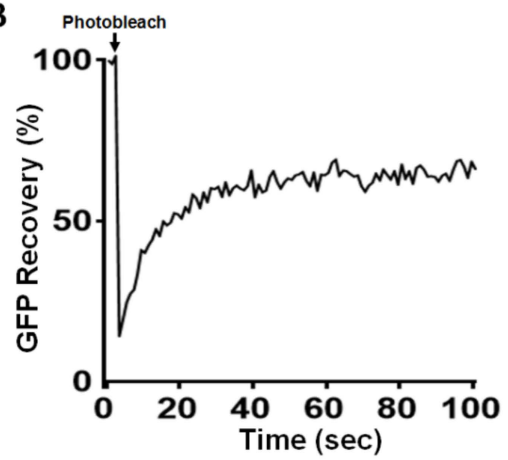

D

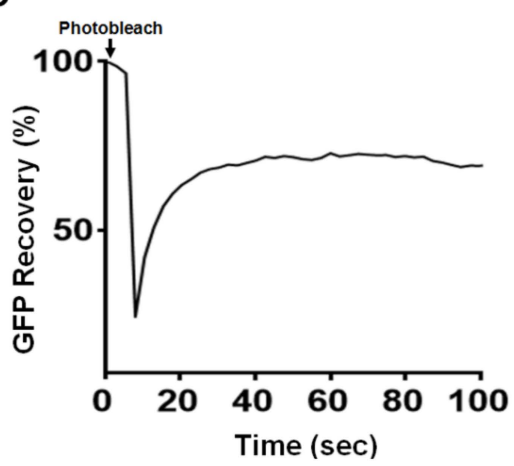

Figure 2. TNTs facilitate intercellular transfer and recipient cell entry of mutant KRAS. Photobleaching was performed $24 \mathrm{~h}$ after cells were placed in co-culture. Images were captured using a $60 \times$ oil immersion objective lens of a Nikon A1Rsi confocal microscope. Scale bars $=2 \mu \mathrm{m}$. (A) Fluorescence confocal microscopy and fluorescence photorecovery after bleaching (FRAP) analysis of GFP-KRAS G12D trafficking within LOVO TNTs. GFP-tagged mutant KRAS transfected LOVO cells were co-cultured with CellTracker Red labeled HCT-8 cells; fluorescence confocal microscopy was performed to visualize recovery of fluorescent signals after photobleaching of the area indicated by the area in the rectangle. (B) Quantitation of fluorescence photorecovery of the area shown in panel A. The time point of immediate loss of GFP expression occurred at $\mathrm{T}=0$, after bleaching. GFP fluorescence intensity recovery is graphed as a percentage of initial expression. (C) Fluorescence confocal microscopy and FRAP of GFP-KRAS ${ }^{\mathrm{G} 12 \mathrm{D}}$ visualized at the point of contact of the TNT with the plasma membrane of a recipient HCT- 8 cell. The square dotted lines indicate the photobleached region at point of contact.

(D) Quantitation of fluorescence photorecovery of the area shown in panel (C).

\subsection{Mutant RAS Predominantly Trafficks through rather than along TNTs}

The current paradigm of KRAS localization as a whole is that the protein is physically connected to the inner leaflet of the plasma membrane. TNTs are extracellular extensions of that plasma membrane and the cell body; thus, membrane-bound isoforms of KRAS may not necessarily need to separate from the membrane to traffic through TNTs. In addition, we previously showed that vesicles such as exosomes engulfed by cells can traffic through or along TNTs [23]; it is conceivable that proteins including RAS may traffic through TNTs within endosomal vesicles. To determine whether mutant KRAS trafficks through or along TNTs, we examined the KRAS4b isoform because this isoform mainly localizes to the plasma membrane whereas the $4 \mathrm{a}$ isoform is predominant in the cytoplasm [40]. We utilized HeLa cells as a model system, and confirmed the presence of TNTs using confocal fluorescent and TIRF-based microscopy using GFP-KRAS G12D -expressing HeLa cells. TNTs formed above the culture glass surface at approximately $3.5 \mu \mathrm{m}$, out of range of the evanescent wavefront (Figure S3). Atomic force microscopy (AFM) further elucidated vesicular bulges characteristic of cellular cargo in transit, and also the rough texture of TNT ultrastructure. In particular, the base of the TNTs displayed a series of smaller protrusions that we postulate act as a scaffold that supports 
the suspension of these non-adherent protrusions, similar to recent reports on membrane tethers using AFM and TNTs using cryo-electron microscopy (Figure S3) [41,42]. We then used JF 646 tagged Halo-KRAS4b (N-terminal) and GFP2-cytoskeleton dual labelled HeLa cells to specifically examine KRAS4b movement. We found that KRAS isoform $4 \mathrm{~b}$ was in fact in constant motion inside the cell and through actin-based protrusions consistent with TNTs. In the accompanying images, the fluorescent KRAS isoform is moving away from the HeLa cell (Figure 3A, Video S3). This finding supports the notion that RAS protein is mobile within the cell, away from the plasma membrane, and that this mobility extends outside of the cell body via cytoplasmic protrusions such as TNTs.
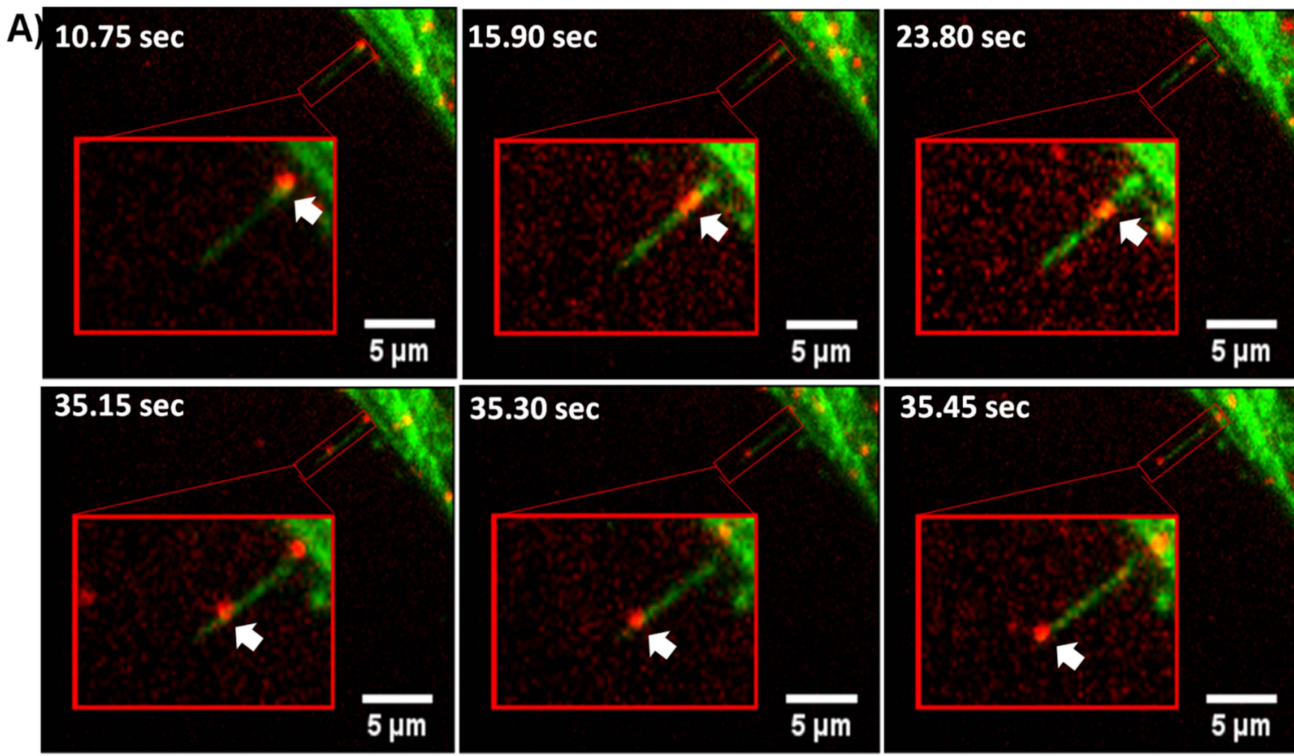

B)

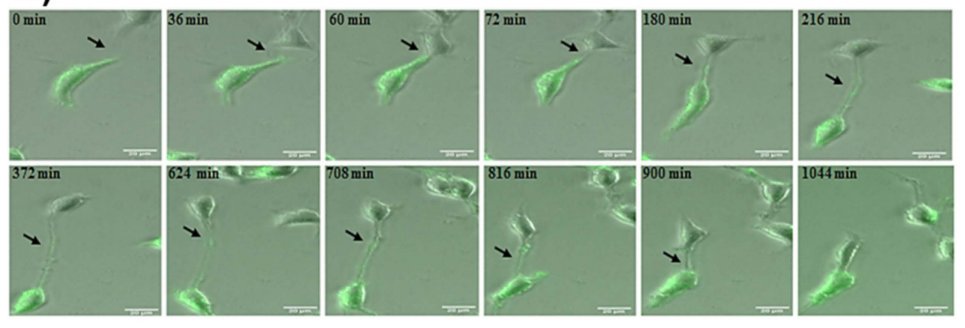

C)

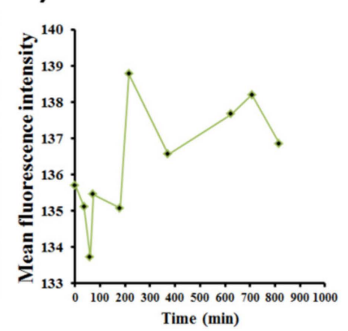

Figure 3. Visualizing intercellular transport of mobile $K R A S$ using fluorescence microscopy. (A) Fluorescent imaging of two-color JF646-dyed KRAS-halo and GFP2 cytoskeleton imaged with the Nikon N-STORM microscope demonstrating RAS motility within actin-based cell protrusions. White arrows indicate actin-based protrusions consistent with TNTs. Scale bars $=5 \mu \mathrm{m}$. (B) Time-lapse microscopy of a GFP mutant KRAS-positive HCT-8 cell using a TNT to transfer mutant KRAS to an HCT-8 cell not expressing GFP mutant KRAS. Scale bar $=20 \mu \mathrm{m}$. (C) Graph demonstrating fluctuation of GFP mutant $K R A S$ expression within the recipient cell during the indicated time interval. Measurements are reported as mean fluorescence intensity, assessed as corrected total cell fluorescence/area (see Section 4 for details).

\subsection{Non-Membrane Bound KRAS Is Mobile and Can Be Trafficked between Cells via TNTs}

To further examine whether TNTs contribute to KRAS heterogeneity between cells by redistributing mutant KRAS to wild-type KRAS tumor cells, we co-cultured HCT-8 cells transfected with mutant KRAS and non-transfected HCT-8 cells. We then performed fluorescence time-lapse microscopy during a 24-h period. We captured instances of TNT formation between cells and measured direct transmission of GFP-tagged mutant KRAS from cell-to-cell (Figure 3B, Video S4). Using Image J software, we measured GFP fluorescence intensity contained within the recipient cell in each image over time 
(Figure 3C); the fluorescence at each time point was a surrogate measure for concentration of mutant KRAS protein co-expressed with the GFP. We found that the overall intensity of GFP-KRAS increased during $15 \mathrm{~h}$; however, the increase was not linear. There were spikes in fluorescence due to dynamic transfer of the GFP-KRAS through the TNT, with points of lower intensity reflecting the transient nature of this transfer. These findings indicate that mutant KRAS promotes TNT formation between cells and that formation of these TNTs facilitates the direct intercellular transfer of mutant KRAS.

\subsection{Mutant KRAS Is Transferred from More Aggressive to Less Aggressive CRC Cells}

After establishing that TNTs are involved in intercellular trafficking of mutant $K R A S$, we sought to determine whether the transfer of mutant KRAS to wild-type KRAS CRC cells can induce a lasting functional effect by dysregulating downstream molecular signaling in recipient cells. First, we co-cultured LOVO cells transfected with GFP-tagged $K R A S^{\mathrm{G} 12 \mathrm{D}}$ construct with HCT-8 cells transfected with NucBlue nuclear stain and mCherry red fluorescent protein in a 1:1 ratio for 48 hours (Figure 4A, left panel).

\section{A}
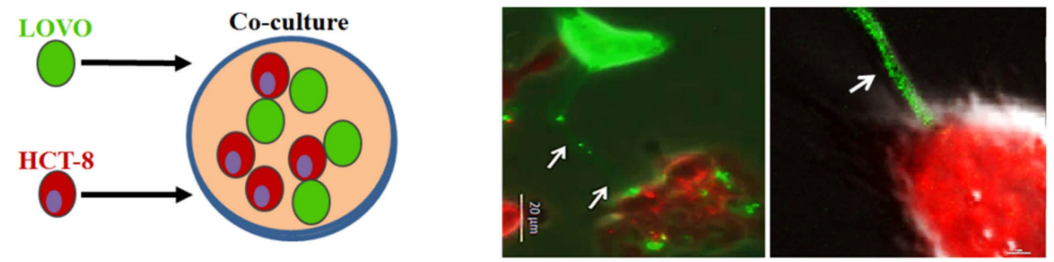

B
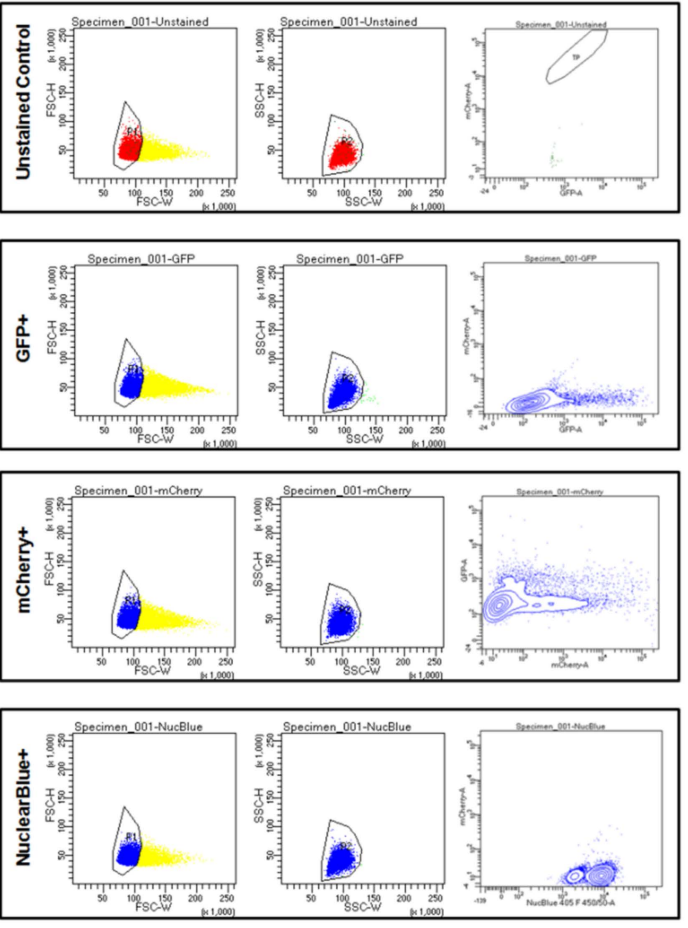

C

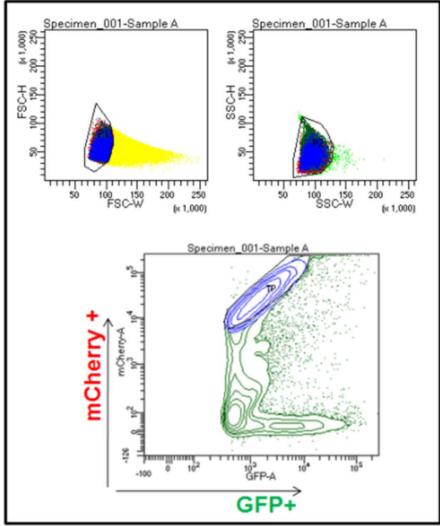

D 3

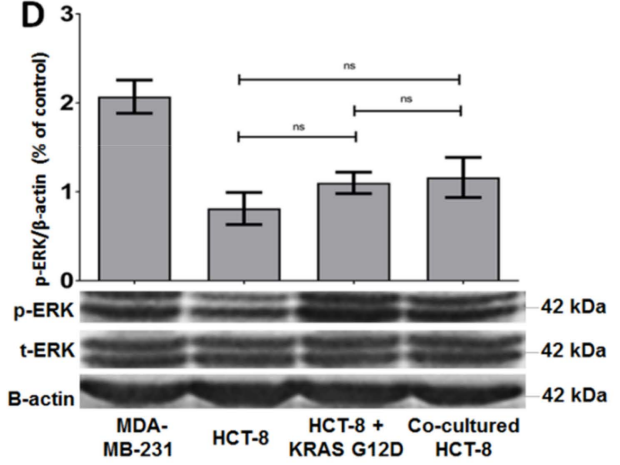


Figure 4. Transfer of mutant KRAS from LOVO cells to HCT-8 cells increases ERK phosphorylation and TNT formation in HCT-8 cells. (A) Schematic of the LOVO and HCT-8 cell co-culture. LOVO cells transfected with GFP-tagged mutant $K R A S^{\mathrm{G} 12 \mathrm{D}}$ were co-cultured with HCT-8 cells labeled with Nuclear Blue and mCherry red fluorescent protein. (B) FACS-based analysis of mutant KRAS transfer between the two cell lines. The four sets of dot plots depict live-cell, single-cell gating for each possible cell population. (C) Flow cytometric scatter dot plots of triple-positive HCT-8 cells. Live single events were selected for sorting based on high forward scatter (FSC) and side scatter (SSC) intensity values. Extracted HCT-8 cells positive for GFP, mCherry, and NucBlue were post-sorted to determine the purity of this population. The mixed triple-positive population represented $2-4 \%$ of the total sorted cell population. (D) Quantitative Western blot analysis of ERK phosphorylation in HCT-8 cells to examine the effects of mutant KRAS acquisition. The MDA-231 cell line was used as a positive control for high ERK activity. (HCT-8 + KRAS G12D vs. HCT-8: $p$-value = 0.4303; Co-cultured HCT-8 vs HCT-8: $p$-value = 0.4749; Co-cultured HCT-8 vs. HCT-8 + KRAS G12D: $p$-value = 0.7414).

Fluorescence microscopy revealed TNT-mediated interaction between the two cell populations (Figure $4 \mathrm{~A}$, middle and right panels). After 48 hours in co-culture, we separated triple-positive (GFP, NucBlue, mCherry) HCT-8 cells by fluorescence-activated cell sorting (FACS). The nuclear marker NucBlue was used to distinguish cells that transferred KRAS versus those that received it. FACS analysis demonstrated that transfer of mutant $K R A S$ occurred, with the mixed triple-positive population representing $2-4 \%$ of the total sorted cell population (Figure $4 B, C$ ).

In separate co-culture experiments, blockade of TNTs with or without an actin-destabilizing agent between LOVO and HCT-8 cells reduced the triple-positive population to approximately $1.2 \%$ and $0.1 \%$, respectively (Figure S4). Western blot analysis confirmed harvested HCT-8 cells acquired G12D KRAS protein during co-culture (Figure S5). Taken together, these experiments demonstrate that cells expressing mutant KRAS can transfer mutant KRAS to wild-type KRAS CRC cells and that this transfer is reduced when TNT formation between the two cell populations is diminished physically and pharmacologically.

\subsection{Intercellular Acquisition of Mutant KRAS Increases ERK Phosphorylation in Recipient Wild-Type CRC Cells}

Mutated RAS regulates the MAPK signaling cascade that induces ERK activation, in part via hyperphosphorylation. We tested whether intercellular transfer of mutant $K R A S$ results in upregulation of ERK phosphorylation in recipient cells that express wild-type RAS. We examined sorted HCT-8 cells after co-culture with KRAS mutant LOVO cells, HCT-8 cells cultured alone, HCT-8 cells directly transfected with $K R A S^{\mathrm{G} 12 \mathrm{D}}$ construct, and MDA-MB-231 cells. Acquisition of mutant KRAS via coculture with LOVO cells elicited a 35\% increase in ERK phosphorylation as compared to HCT-8 cells cultured alone (Figure 4D; full western blot and densitometry readings are provided in Figure S6). The protein expression in HCT-8 cells that acquired G12D after co-culture was higher than protein expression in HCT-8 cells transfected directly with GFP-KRAS G12D. The reason for this difference is that the latter group was analyzed post-transfection without cell sorting, and the transfection efficiency was not $100 \%$. The former group was a FACS-sorted (purified) cell population post-transfection; and thus, it demonstrated higher expression.

\subsection{Mutant KRAS Increases TNT Formation and Reduces Cell Size in Recipient Wild-Type KRAS Cells}

To test whether acquisition of mutant KRAS affects TNT formation potential, HCT-8 cells were cultured alone, directly transfected with KRAS G12D construct, or co-cultured with mutant G12D-expressing LOVO cells (Figure 5A). We first quantified the area of HCT-8 cells and found a decrease in cell area by 48 and $72 \mathrm{~h}$, but not by $24 \mathrm{~h}$ (Figure $5 \mathrm{~B}-\mathrm{D}$ ); this finding suggests that the effect of mutant KRAS transfer on cell morphology was not immediate. We then determined the rate of TNT formation after acquisition of oncogenic KRAS at 24, 48, and $72 \mathrm{~h}$. 
A)
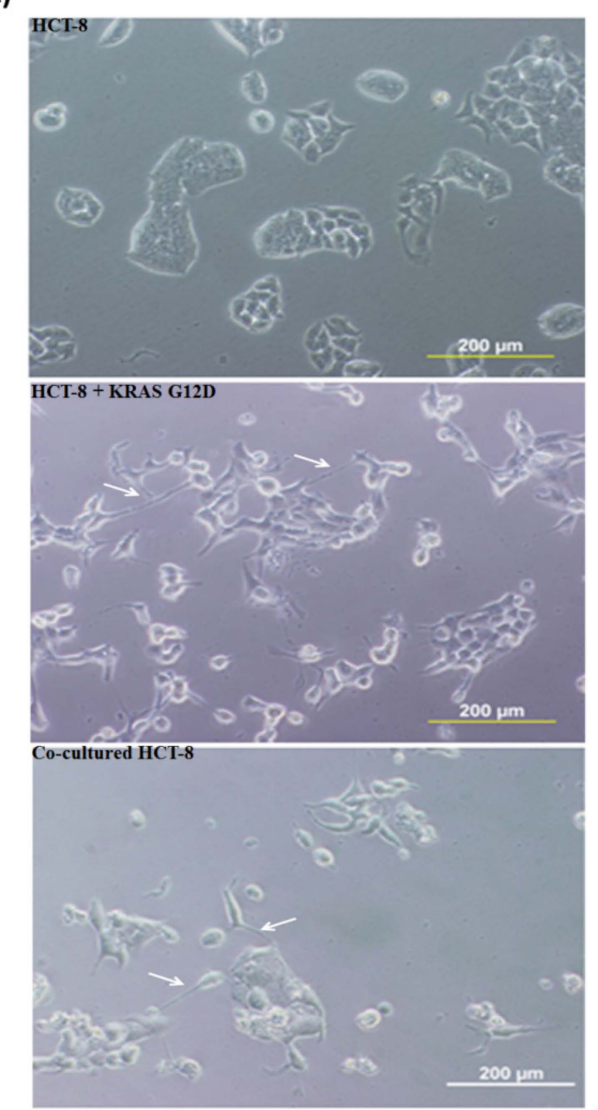

B)
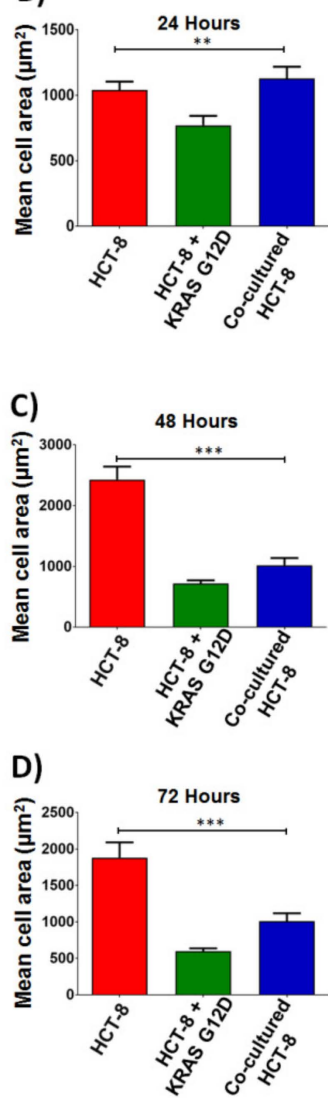

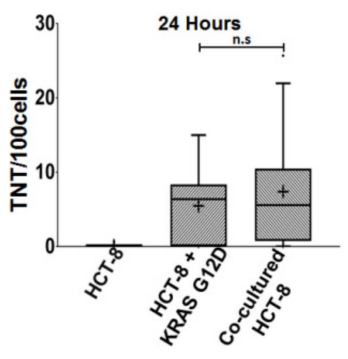

48 Hours
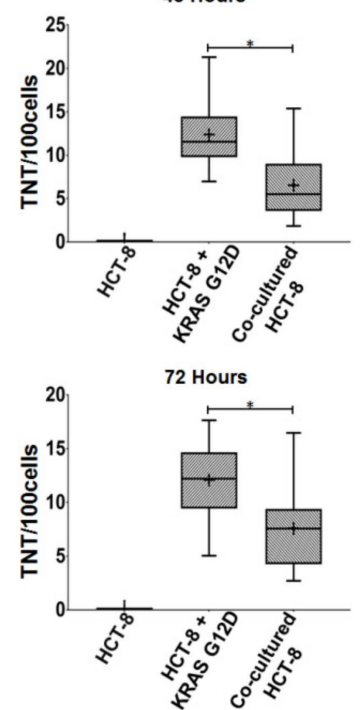

Figure 5. Effects of acquisition vs intercellular transfer of mutant KRAS on cell area and TNT formation in recipient colon cancer cells. (A) Representative phase contrast microscopy of native HCT-8 cells, HCT-8 cells post-transfection with KRAS G12D, and HCT-8 cells co-cultured with mutant G12D-expressing cells. Cells were examined at $24 \mathrm{~h}$ intervals to measure cell size and TNT formation. Changes in mean HCT-8 cell size are shown in the left-hand panels at (B) $24 \mathrm{~h},(\mathbf{C}) 48 \mathrm{~h}$, and (D) $72 \mathrm{~h}$ after transfection or co-culture. Boxplot representation of TNTs per 100 HCT- 8 cells is shown in the right-hand panels at (B) $24 \mathrm{~h},(\mathbf{C}) 48 \mathrm{~h}$, and (D) $72 \mathrm{~h}$. Asterisks indicate statistical significance with $p$-value $<0.05$ (see Statistical Analysis in the Section 4 for details); n.s. = not statistically significant $(p>0.05)$; per GraphPad Prism standards, ${ }^{*}$ indicates $p \leq 0.05 ;{ }^{* *}$ indicates $p \leq 0.01{ }^{* * *}$ indicates $p \leq 0.001$.

Acquisition of G12D KRAS by either transfection or co-culture significantly upregulated TNT formation in recipient HCT-8 cells at all three time points (Figure 5B-D). The difference between transfected vs. co-cultured cells compared to baseline was significant at 48 and $72 \mathrm{~h}$ (Table 2). These findings demonstrate that transfer of mutant KRAS results in changes in cell morphology, including TNT formation. To further confirm that acquisition of mutant KRAS affects TNT formation, we transfected HCT-8 cells with a plasmid expressing the G12D variant of KRAS co-expressed with green fluorescent protein (GFP). As a negative control, we separately transfected HCT-8 cells with a GFP-plasmid. We noted morphologic differences in the cells transfected with KRAS ${ }^{\mathrm{G} 12 \mathrm{D}}$ (Figure 6A). HCT-8 cells that had acquired G12D KRAS displayed an altered morphology more characteristic of mesenchymal or fibroblast cells (i.e., more elongated, linear, and spindle-like than epithelial cells) as compared to native HCT-8 cells. HCT-8 cells transfected with G12D KRAS also formed significantly more TNTs per 100 cells than non-transfected cells or the GFP control at 24, 48, and $72 \mathrm{~h}$ (Figure 6B-D). 
Table 2. Statistical analysis comparing HCT-8 cells either transfected with KRAS G12D or co-cultured with KRAS G12D-harboring HCT-8 cells, compared to native HCT-8 cells. $t$-test analysis was performed using GraphPad Prism. $p$-values $<0.05$ were considered significant.

\begin{tabular}{cccc}
\hline Figure & Comparison Groups & Cells Examined & $p$-Value \\
\hline $5 \mathrm{~B}(24 \mathrm{~h})$ & HCT-8 & $\begin{array}{c}\text { HCT-8 }+ \text { KRAS G12D } \\
\text { (green bar) }\end{array}$ & $p=0.0080$ \\
\hline $5 \mathrm{~B}$ & HCT-8 & Co-cultured HCT-8 & $p=0.4263$ \\
\hline $5 \mathrm{C}(48 \mathrm{~h})$ & HCT-8 & $\begin{array}{c}\text { HCT-8 }+ \text { KRAS G12D } \\
\text { (green bar) }\end{array}$ & $p=0.0001$ \\
\hline $5 \mathrm{C}$ & HCT-8 & Co-cultured HCT-8 & $p=0.0001$ \\
\hline $5 \mathrm{D}(72 \mathrm{~h})$ & HCT-8 & $\begin{array}{c}\text { HCT-8 }+ \text { KRAS G12D } \\
\text { (green bar) }\end{array}$ & $p=0.0001$ \\
\hline $5 \mathrm{D}$ & HCT-8 & Co-cultured HCT-8 & $p=0.0005$ \\
\hline
\end{tabular}

A
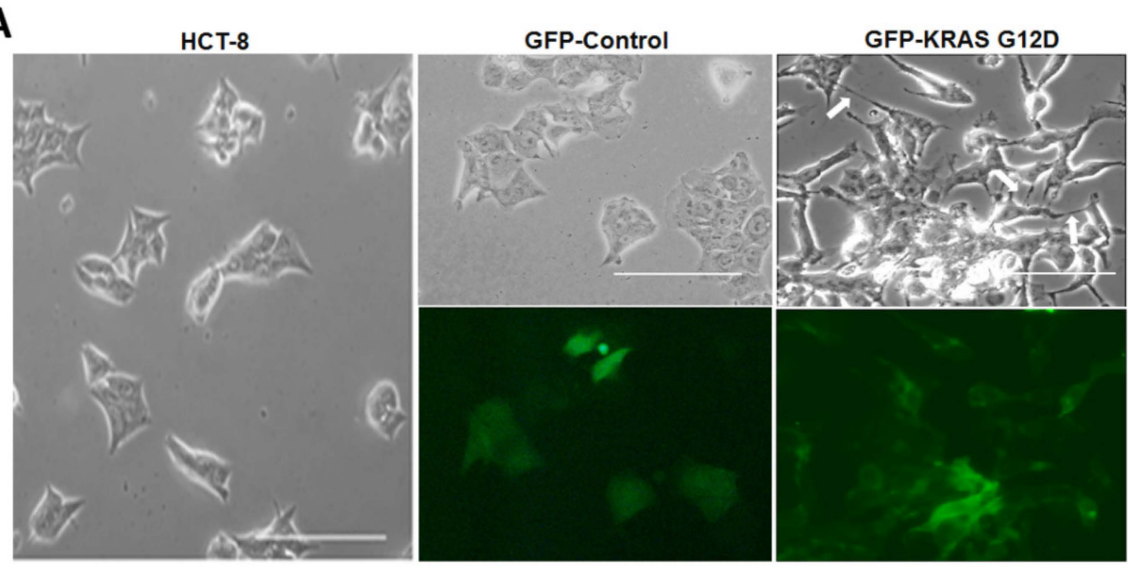

B

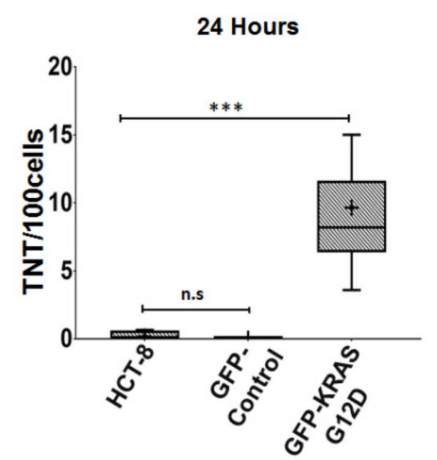

C

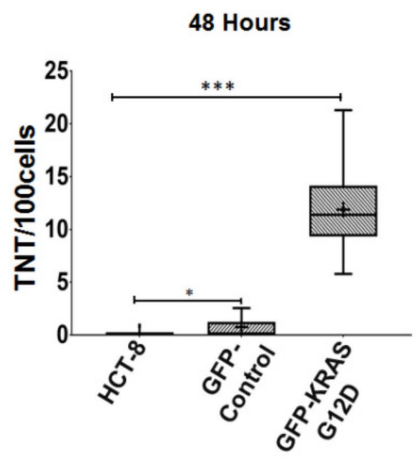

D

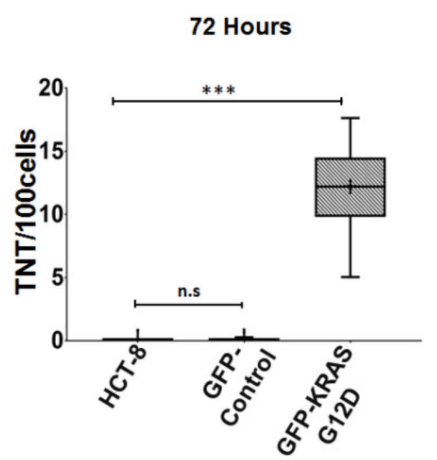

Figure 6. Mutant KRAS is associated with higher TNT formation among HCT-8 cells. (A) Representative phase contrast and fluorescence microscopy images of HCT-8 cells, HCT-8 cells transfected with GFP-control plasmid, and HCT-8 cells transfected with GFP-KRAS G12D mutant. (B-D) Boxplot representation of TNTs per 100 cells over (B) $24 \mathrm{~h}$, (C) $48 \mathrm{~h}$, and (D) $72 \mathrm{~h}$. Quantification of TNTs was performed using methods similar to Figure 1. Symbols on the boxplot are as follows: Box, 1st to 3rd (Q1-Q3) Quartiles; + = Mean; Line inside box = Median. Asterisk symbol indicates statistical differences in median value; n.s = non statistically significant.

\section{Discussion}

Horizontal transmission of oncogenes, and oncogenic proteins, is a relatively novel topic of study in the larger field of intercellular communication in cancer that merits further evaluation for its 
potential role in creating highly heterogeneous tumor microenvironments. Intercellular transfer of oncogenic RAS has been examined in a few studies, with this transport occurring via extracellular vesicles [12,13] and even TNTs connecting immune cells $[15,16,37]$. The downstream effects of this transfer, and the role of TNTs in mediating this process in colon cancer particularly, have hitherto been unclear. Our study builds upon prior studies by examining the ability of TNTs to mediate intercellular transfer of mutant KRAS protein in colon cancer cells with endogenous wild-type KRAS. A schematic depicting this process is provided in Figure S7.

We recently reported that TNTs can be imaged in CRC resected from human patients [25]. Our present study assesses TNT formation in multiple CRC cell lines with various invasive potential in vitro. Our data demonstrate that mutant KRAS can be transported between CRC cells and that TNTs represent one mechanism for facilitating direct cell-to-cell transfer between mutant KRAS and wild-type KRAS CRC cells. Further, the acquisition of mutant KRAS by wild-type KRAS CRC cells accelerated the rate of TNT formation and activated downstream molecular signaling in the RAS pathway. The transfer of RAS along the filamentous actin, which provides the structural basis of TNTs, is not surprising because it has been shown that high levels of activated RAS trigger cellular protrusions [43]. In that study, it was reported that RAS activation leading to extension of protrusions induces a positive feedback loop. This finding is consistent with our results that KRAS mutant CRC cells have upregulated TNT formation, and in turn, these TNTs facilitate intercellular transfer of mutant KRAS. In addition, we co-cultured GFP-tagged mutant KRAS-expressing CRC cells with wild-type KRAS CRC cells (labeled red). GFP-mutant KRAS fluorescence was detected for at least 7 days after the start of co-culture. This transfer also led to changes in cell morphology, including decreases in mean cell area, suggesting sustained cellular changes. One remarkable morphological change occurred when acquisition of mutant KRAS stimulated a quantifiable increase in the average number of TNTs per cell in wild-type cells. The results suggested that intercellular transfer of mutant KRAS led to changes in cell phenotype that were associated with increased TNT-mediated intercellular communication. Most notably, the higher rate of TNT formation among these cells was not dependent on cellular proliferation.

Our findings suggest that there is significant heterogeneity of TNT formation among CRC cell types. The malignant cell lines LOVO and HCT-116 both harbor KRAS G13D and formed the most TNTs. LOVO cells formed significantly more TNTs over time than HCT-116. We noted that LOVO is derived from a metastatic CRC tumor, and HCT-116 from a primary colon tumor; the metastatic phenotype is more invasive, and this property may account for this difference. However, the wild-type malignant cell line HCT- 8 also formed a small but nonetheless quantifiable amount of TNTs. In examining other common genetic factors among these three CRC cell lines forming TNTs (LOVO, HCT-116, HCT-8), we noted that each of these cell lines is also marked by deficiency of mismatch repair proteins (dMMR), a genetic factor that can lead to microsatellite instability (MSI) [30,33,34]. Approximately $45 \%$ of MSI/dMMR cases also harbor mutations in KRAS [44-46]. Among our three CRC cell lines forming TNTs, LOVO cells harbor MSI and G13D KRAS and are derived from a metastatic lesion; this cell line formed significantly more TNTs than HCT-116 and HCT-8; HCT-116 is characterized by MSI and G13D KRAS, but derived from a primary tumor, and HCT- 8 is characterized by only MSI. Therefore, metastatic colon cancer cells harboring the combination of mutant KRAS along with MSI displayed a higher potential for forming TNTs, a highly relevant finding in light of recent evidence that MSI-high tumors are more strongly susceptible to immune checkpoint inhibitor therapy than microsatellite stable (MSS) tumors [47].

The molecular drivers and genomics associated with CRCs have been better elucidated in recent years, including significant characterization provided by The Cancer Genome Atlas Network (TCGA) [48]. Recent advances in the molecular classification of CRCs are highly clinically relevant, with more widespread adoption of next-generation sequencing and All-RAS testing to identify additional isoforms of KRAS and NRAS. CRC tumors were previously classified mainly into several molecular subtypes that included chromosomal instability, microsatellite instability, and DNA hypermethylation 
or CpG island methylator phenotype (CIMP) [49]. Stratification currently aligns into four molecular subgroups that are now well described and prominent for their correlation to patient outcomes, including survival [50]. Our study provides insight into the notion that the presence of mutated KRAS, as well as MSI-H tumor status, are associated with increased formation of TNTs. MSI-H CRC cell lines that are commonly used for cancer research have been associated with proximal tumor location (a factor in turn recently correlated with worse prognosis in CRC patients), as well as CIMP-positive status [32]. CRC tumors with positive CIMP, in particular, may in turn involve cytoskeletal remodeling regulated by key RAS-associated proteins, such as oncogenic RASSF1A (Ras-association domain family isoform), a tumor suppressor whose loss has been recently implicated in TNT formation [51]. This combination of molecular and cellular alterations undoubtedly influences the evolving tumor microenvironment, both prior to and following cancer-directed treatment of such tumors.

RAS regulates MAP-kinase signaling pathway that relays information from the surface of the cell to the nucleus by way of Ras/Raf/MEK/ERK phosphorylation [52]. The functional transfer of mutant KRAS was demonstrated by a 35\% increase in the phosphorylation of ERK in KRAS wild-type cells after transfer of oncogenic KRAS. The long-term implications of this downstream effect are yet unknown; recent studies evaluating transfer of oncogenic H-ras via extracellular vesicles from transfected intestinal (non-malignant) epithelial cells detected an ability of this transfer to regulate recipient endothelial cells, but not to induce malignant transformation [13]. The authors of that study suggested that despite this fact, malignant cells preferentially received and were affected by these Ras-carrying vesicles, and that finding is consistent with our observation in this study detecting differences in downstream molecular regulation of the RAS pathway in recipient colon cancer cells. A separate and more recent study showed that intercellular transfer of KRAS via extracellular vesicles failed to induce any meaningful effects in recipient cells [53]; thus, it is clear that with relatively disparate results across cell types, and even using different members of the RAS family (KRAS and $H R A S$ ), these cumulative studies performed to date raise important questions regarding efficiency of transfer, whether a minimum amount of transported RAS cargo is required to initiate short- or long-term alterations in recipient cells, and whether cellular and molecular properties are altered in malignant cells alone as compared to non-malignant cells.

It is well known that the effects of oncogenic mutant KRAS can also be mediated by noncanonical signals via multiple pathways [54], and therefore, the gene transfer can be inferred to have pleiotropic effects beyond MAPK signaling. These findings have implications well beyond just colon cancer, as indeed transfer of oncogenic RAS may be a newly identified hallmark of many other types of RAS-driven cancers. Mueller et al. recently reported that allelic imbalance and increased oncogenic dose of RAS increases metastatic potential in pancreatic carcinomas [55], and the intercellular transfer of oncogenic RAS may be one modality by which this imbalance is achieved. These findings also have important implications for fully understanding intercellular communication in cancer. Intriguingly, increased expression of the RAS oncogene product has been associated with downregulation of gap junction intercellular communication (GJIC) [56-59]. As GJIC occurs between cells in immediate proximity, the downregulation and abrogation of these connexin channel-lined junctions may lead to increased intercellular cross-talk mediated by TNTs among RAS-expressing cells.

It is well established that KRAS signaling induces changes in the extracellular matrix that are highly conducive to tumor expansion and metastasis [60]. Our finding that CRC cells transfer a tumor-driving mutant molecule to other cells is consistent with previous observations that TNTs formed between immune-related cells [15]. KRAS is present in recycling endosomes, but localizes to the plasma membrane when active [61]. Reports of RAS transfer have involved the sharing of membrane patches, similar to the process known as trogocytosis [62], as well as intercellular transport of oncogenic RAS via extracellular vesicles [12,13].

The results we present here suggested that oncogenic mutant KRAS increases TNT-mediated cross-talk between colon cancer cells and that these cells harness these TNTs to further disperse KRAS molecules to other wild-type KRAS colon cancer cells. Demonstrating horizontal transfer of KRAS 
represents a highly novel and transformative shift in the current paradigm that driving mutations only occur either through vertical transmission or come about spontaneously through mutation. This is a finding that may explain how proportions of mutant subclones can be dynamic over time and with tumoral evolution and also why mutant RAS localizes to regions of highest invasive potential in CRC [8].

\section{Materials and Methods}

\subsection{Cell Lines and Cell Culture}

LOVO, HCT 116, SW480, and HT-29 cell lines were acquired from the American Type Culture Collection (ATCC, Rockville, MD, USA). The colon cancer HCT-8 cell line was kindly provided by Dr. Timothy Starr at the University of Minnesota. The AAC1 adenoma cell line was provided by Dr. Subbaya Subramanian at the University of Minnesota. The LOVO cell line is a human G13D KRAS mutant colon cancer cell line derived from a distant (supraclavicular) metastasis [26]. HCT 116 is a human G13D KRAS mutant colon carcinoma derived from a primary tumor [26]. SW480 is a G12V KRAS mutant colon cancer cell line derived from a primary tumor [63]. HCT-8 and HT-29 are $K R A S$ wild-type human colon carcinoma cell lines derived from primary tumors [26,30]. AAC1 is a non-malignant, KRAS wild-type human colon adenoma cell line [64]. Three of these cell lines have also been identified to exhibit microsatellite instability (LOVO, HCT 116, HCT-8). Authentication of cell lines was performed by the Core Fragment Analysis Facility at Johns Hopkins University using short tandem repeat (STR) profiling. Cell lines were confirmed to be negative for mycoplasma contamination within six months of use. Please see Table 1 (in Section 2) for further details.

LOVO cells were maintained and passed using Ham's F-12 medium supplemented with 10\% FCS, vitamins, antibiotics, and glutamine; HCT-8 and HCT116 cells were maintained in Dulbecco's modified Eagle's medium (DMEM) supplemented with 10\% fetal bovine serum (FBS; Invitrogen Life Technologies, Carlsbad, CA, USA), and 1\% Antibiotic-Antimycotic (anti-anti; Gibco Life Technologies, Gaithersburg, MD, USA). All cell lines were incubated in a humidified incubator at $37^{\circ} \mathrm{C}$ supplied with $5 \%$ carbon dioxide.

\subsection{Transfections}

For transfections, RAS expression clones CMV51p > mCherry-Hs.KRAS and CMV51p > eGFP-Hs.KRAS G12D were obtained from the RAS Program at the NCI's Frederick National Laboratory for Cancer Research (FNLCR, Frederick, MD, USA). This clone specifically co-expressed GFP with the G12D variant of KRAS. Cell lines were grown in passaging medium without antibiotics to 70-90\% confluence at the time of transfection. Transfection was performed 24 hours after plating using Lipofectamine 2000 (Invitrogen, Carlsbad, CA, USA) and $2 \mu \mathrm{g}$ of plasmid DNA in Opti-MEM ${ }^{\circledR}$ without serum following the manufacturer's instructions. Cells were used in experiments $24-60 \mathrm{~h}$ post-transfection. For co-cultures, LOVO cells transfected with GFP-tagged KRAS G12D and mCherry and Pure Blu Nuclear Staining Dye double-labelled HCT-8 cells were cultured in a 1:1 ratio. Cells were left in culture for 48 hours after which HCT-8 cells were acquired through fluorescence-activated cell sorting and media selection.

\subsection{Quantification of TNTs}

TNTs were visually identified and quantified as previously described [9,20,65-67]. Briefly, these parameters included: (i) lack of adherence to the substratum of tissue culture plates, including visualization of TNTs passing over adherent cells; (ii) TNTs connecting two cells or extending from one cell were counted if the width of the extension was estimated to be $<1000 \mathrm{~nm}$; and (iii) a narrow base at the site of extrusion from the plasma membrane. Cellular extensions not clearly consistent with the above parameters were excluded. Images for TNT analysis were captured on an Olympus IX70 inverted microscope (Olympus Corporation, Center Valley, PA, USA) using the $20 \times$ objective lens in 
15 randomly chosen fields of a 6-well plate at 24, 48, and $72 \mathrm{~h}$. A single representative image taken at all time points for each well was used for analysis of TNT rate, length, and cell proliferation. Experiments were performed in triplicates for each cell line. The number of TNTs per cell (TNTs/cell) was used to represent our findings to exclude the possibility that changes in TNTs were due to increased cell proliferation. ImageJ was used to convert images to 32-bit to correct for color discrepancies. Cells and TNTs were counted manually. Box plots were generated to show the distribution of the data, and medians were compared using the Mann Whitney $U$ test assuming unequal variances. $p$-values $<0.05$ were considered statistically significant.

\subsection{FACS Sorting}

Co-cultured cell samples were harvested and filtered to ensure single-cell suspension in $5 \mathrm{~mL}$ polystyrene test tubes (Falcon, Corning, NY, USA). The final sample was resuspended in RPMI-1640 medium supplemented with 2.5\% FBS. Cell populations of interest were acquired and sorted with a FACSAria II cell sorter (BD Biosciences, Franklin Lakes, NJ, USA) equipped with a $488 \mathrm{~nm}$ laser (50 mW Sapphire Laser; Coherent Inc, Santa Clara, CA, USA), $561 \mathrm{~nm}$ laser (100 mW Sapphire Laser, Coherent Inc., Santa Clara, CA, USA), and 405 nm laser (100 mW OBIS Laser, Coherent Inc., Santa Clara, CA, USA) for GFP, mCherry, and NucBlue excitation, respectively. Using FACSDiva software (BD Biosciences), HCT-8 single-cell events were distinguished and sorted from the population by gating for GFP, mCherry, and NucBlue triple-positive cells with similar FSC/SSC characteristics as the HCT-8 negative control.

\subsection{Time-Lapse Imaging}

For time-lapse imaging of mutant KRAS-positive TNTs, cells (LOVO or HCT-8) were transfected with GFP-KRAS ${ }^{\mathrm{G} 12 \mathrm{D}}$ in a ratio of $1: 1$ and at a density of $3 \times 10^{4}$ cells $/ 35 \mathrm{~mm}$ dish. After $4 \mathrm{~h}$, the dishes were evaluated to ensure even distribution. After $24 \mathrm{~h}$, the dishes were scanned for GFP-KRASG12D and negative cells that were in proximity and could potentially interact via TNTs. These regions of interest were imaged for generative time-lapse movies. In brief, fields of view through a $20 \times$ objective lens were captured using a wide-field Axio200M microscope (Zeiss, Inc., Thornwood, NY, USA) custom-fitted with a stage incubator that maintains environmental conditions at $37^{\circ} \mathrm{C}$ and $5 \% \mathrm{CO}_{2}$. The microscope was set up to capture an image of each chosen field every $10 \mathrm{~s}$ in the differential interference contrast (DIC) and green fluorescent channels for $10 \mathrm{~min}$.

\subsection{Quantification of Fluorescence after Intercellular Transfer of GFP-Tagged RAS}

Changes in GFP fluorescence intensity within the recipient cell were measured using ImageJ software. The cell of interest was selected using the drawing/selection tools (circle tool). From the "Analyze" menu of the software, "set measurements" was used to select "area integrated intensity" and "mean grey value." The GFP fluorescence intensity value was measured for both the cell of interest and the image backgrounds. The data from the "results" window was transferred into a new spreadsheet (MS Excel) and the corrected total cell fluorescence (CTCF) formula was used: CTCF = Integrated Density-(Area of selected cell * Mean fluorescence of background readings).

\subsection{Cell Lysate}

Cells were washed quickly with cold PBS (phosphate buffered saline), scraped from culture plates, and then subjected to centrifugation $(13,000 \mathrm{rpm}, 14 \mathrm{~s})$. The pellets were resuspended in $5 \times$ the pellets' volume of TNESV lysis buffer (50 mM Tris-HCl, pH 7.4; 1\% NP-40; 2 mM EDTA, pH 8.0; $0.1 \mathrm{M}$ $\mathrm{NaCl}$ ) containing protease (Roche, Indianapolis, IN, USA) and phosphatase inhibitors (Sigma-Aldrich, St. Louis, MO, USA) for $10 \mathrm{~min}$ at room temperature. Lysed cells were subjected to centrifugation (13,000 rpm, $14 \mathrm{~s})$, and supernatant was collected. Protein concentrations of lysate were determined by Bradford assay (Bio-Rad, Hercules, CA, USA). 


\subsection{Western Blots}

Proteins were separated by 8 or 10\% SDS-polyacrylamide gel electrophoresis (PAGE) gels. Separated proteins were transferred to polyvinylidene difluoride (PVDF) membranes, and the membranes were blocked in 5\% non-fat dry milk for 1 hour at room temperature in Tris-buffered saline-Tween (TBST: $0.15 \mathrm{M} \mathrm{NaCl}$; $0.01 \mathrm{M}$ Tris-HCl, $\mathrm{pH}$ 7.6; 0.05\% Tween 20). PVDF membranes were then blocked for 1 hour at ambient temperature and then overnight at $4{ }^{\circ} \mathrm{C}$ with primary antibody. Primary antibodies were acquired from Cell Signaling Technology, Inc. (Danvers, MA, USA) and were rabbit Ras (CST\#3965), Ras (G12D Mutant Specific) (SCT \#14429), p44/42 MAPK (Erk1/2) (CST \#9102), and Phospho-p44/42 MAPK (Erk1/2) (CST \#9101). Each antibody was diluted 1:1000 prior to use. Membranes were cut, and each protein of interest was probed separately. Blots were washed three times for $5 \mathrm{~min}$ in TBST before and after incubation with the appropriate horseradish peroxidase labeled secondary antibodies. A LI-COR-Odyssey infra-red scanner (LI-COR Biosciences, Lincoln, NE, USA) was used to visualize the bands of interest. Protein band density was measured by using ImageJ (public domain, https://imagej.nih.gov).

\subsection{Photobleaching (FRAP)}

For FRAP experiments, LOVO colon carcinoma cells were transfected with a plasmid expressing fluorescently labeled GFP-KRASG12D (green). After confirmation of successful transfection and fluorescent signal, these cells were co-cultured with HCT-8 colon carcinoma cells labeled with CellTracker Red. FRAP was performed using a $60 \times$ water immerged objective lens of a Nikon A1Rsi confocal microscope (Nikon Instruments Inc., Melville, NY, USA) A section of interest on GFP-KRAS mutant-positive TNTs (panel A of corresponding Figure 2) was selected and photobleached. In an additional experiment, the frame focused on a CellTracker Red labeled HCT-8 cell connected to a GFP KRAS G12D-expressing LOVO cell, and photobleaching was applied to the point of contact of the TNT with the recipient HCT-8 cell membrane. For both experiments, recovery of the bleached region was monitored and captured though time-lapse image acquisition.

\subsection{Two-color Total Internal Reflection Fluorescence (TIRF) Imaging of KRAS4b}

After culture overnight in a 6-well plate, confluent HeLa cells were dual transfected with Halo-KRAS4b and pCMVLifeAct-GFP2 (ibidi) plasmids and cultured $24 \mathrm{~h}$. Transfected cells were then re-plated onto a glass coverslip and cultured overnight. Halo-KRAS4b-expressing cells were further labeled with the JF646 dye conjugated with the ligand (25 pM), which directly penetrates the cell membrane and covalently binds halo-KRAS4b, by incubating at $37^{\circ} \mathrm{C}$ for $30 \mathrm{~min}$ and followed by washing with PBS $(1 \times)$ three times before imaging.

The two-color KRAS4b and cytoskeleton were imaged with a Nikon N-STORM microscope. Halo-KRAS4b (tagged with JF646 dye) molecules and the actin cytoskeleton (GFP2) were excited simultaneously by the $647 \mathrm{~nm}$ and $488 \mathrm{~nm}$ lasers, respectively, under TIRF mode, while the emissions from the two fluorophores were split into the green and far red channels through the Gemini light splitting system (Hamamatsu, Bridgewater, NJ, USA). The two channel signals were recorded in separate areas of the EMCCD camera (DU888, Andor, Concord, MA, USA) at the frame rate of $20 \mathrm{fps}$. The two-color channel registration was calibrated with $200 \mathrm{~nm}$ tetraspeck fluorescent beads (Life Technologies, Carlsbad, CA, USA) before image acquisition. Image processing was performed to combine the two channel images into a color image stack and made into movie.

\subsection{TIRF Imaging of HeLa Cells}

Differential interference contrast (DIC) images were captured using a Zeiss Widefield microscope in TIRF acquisition mode with a Photometrics DV2/camera imaging system. Images were captured with an alpha Plan-Apochromat100 $\times$ Oil objective lens with a numerical aperture of 1.46 and 1.6 
optovar magnification. Live cells were cultured on a $35 \mathrm{~mm}$ Mattek dishes \#1.5 (MatTeK Inc., Ashland, MA, USA) within an imaging chamber at $37^{\circ} \mathrm{C}$ and $5 \% \mathrm{CO}_{2}$.

\subsection{Cell Preparation for Atomic Force Microscopy}

HeLa cells were fixed for $10 \mathrm{~min}$ in $2.5 \%$ glutaraldehyde, then washed three times with PBS. Cells were then kept in PBS for atomic force microscopy imaging in a $50 \times 9 \mathrm{~mm}$ Petri dish (product number 351006, BD Falcon, Corning, NY, USA). Atomic force microscopy images were obtained using a MFP-3D-BIO Atomic Force Microscope (Oxford Instruments, Abingdon, UK).

\subsection{Statistical Analysis}

The overall median of TNTs/cell and lengths over three days was compared using the Wilcoxon Rank Sum tests due to the non-normal distribution of data. $p$-values were conservatively adjusted for multiple comparisons within each experiment using a Bonferroni correction. Analyses were conducted using GraphPad Prism version 7 (GraphPad Software, Inc., La Jolla, CA, USA), and p-values $<0.05$ were considered statistically significant. Prism uses the following symbols indicating extent or lack of statistical significance: ns indicates $p>0.05 ;{ }^{*}$ indicates $p \leq 0.05 ;{ }^{* *}$ indicates $p \leq 0.01 ;{ }^{* * *}$ indicates $p \leq 0.001 ;{ }^{* * *}$ indicates $p \leq 0.0001$.

\section{Conclusions}

In conclusion, our investigation of the intercellular transfer of KRAS via TNTs has elucidated a novel mechanism by which a tumor-driving mutant protein can be trafficked and distributed among cancer cells, in this case colon cancer cells specifically. This intercellular transfer induces intracellular heterogeneity of mutant KRAS in cells with endogenous wild-type KRAS. This finding has strong implications for the ability of TNTs and other modes of intercellular transfer to potentially reprogram malignant and stromal cells in the surrounding tumor microenvironment. Furthermore, as oncogenic RAS signaling has profound effects on modulating the tumor microenvironment, including cancer-associated fibroblasts, immunogenic anti-tumor response, and angiogenesis [60], amplification of the influence of oncogenic RAS via intercellular transfer of this oncogene and its products may have important consequences for tumor progression. Effective therapeutic drugs targeting RAS signaling are desperately needed, as the RAS oncogene drives $30 \%$ of all cancers [68]. If TNTs mediate this transfer, then therapeutically targeting these structures by preventing formation and/or disassembling of these cellular conduits represents a novel therapeutic strategy for modulating oncogenic signaling.

Supplementary Materials: The following are available online at http://www.mdpi.com/2072-6694/11/7/892/s1: Figure S1: (A) Differences in cellular proliferation for each cell line. (B) Additional representative phase contrast microscopy images of especially long TNTs forming between LOVO cells. Scale bar $=200 \mu \mathrm{m}$. Figure S2: Transfection of GFP alone (upper left panel) into LOVO cells does not induce changes in cellular morphology, whereas transfection with GFP-tagged mutant KRAS (KRAS $\left.{ }^{\mathrm{G} 12 \mathrm{Vmut}}\right)$ upregulates formation of TNTs and TNT-like protrusions. Additional representative inverted fluorescence microscopy images of $K R A S^{\mathrm{G} 12 \mathrm{~V}}$-expressing LOVO cells are provided in the bottom panels. Figure S3: (A) Representative TIRF-based microscopy images demonstrating the non-adherent characteristic of TNTs and the technical challenge of for performing single molecule tracking analysis of KRAS within TNTs. (B) Cartoon depiction of TIRF microscopy and the inability of the TIRF-generated evanescent field to reach TNTs above the substratum. FRAP analysis demonstrating recovery of GFP-KRAS G12D . (C) High resolution confocal microscopic image of HeLa cells connected at long range via a TNT. Note characteristic bulges of intra-TNT vesicles in transit on the right half of the TNT, as well as shorter actin-based adherent stress fibers on both cells, providing contrast to the much longer and non-adherent TNT. Scale bar $=2 \mu \mathrm{m}$. (D) Atomic force microscopy (AFM) imaging of TNTs connecting HeLa cells further elucidates the ultrastructure of TNTs, including at the point of entry/extrusion from cells. Insets include Phase-Contrast Microscopy version of the same cells for comparison, and close-up views of the base of the TNT and point-of-contact with both cells. Figure S4: FACS-based analysis of mutant KRAS transfer between the two cell lines when cell culture medium was treated with (A) or without (B) cytochalasin D (an actin-destabilizing agent that reduces TNT numbers in vitro [69,70]). LOVO and HCT-8 cells were cultured in separated compartments using a semipermeable transwell culture insert with $0.4 \mu \mathrm{m}$ diameter pores. The insert allows for free diffusion of culture media contents. Figure S5: Western blot analysis using a KRAS G12D mutant specific antibody for qualitative demonstration of acquisition of mutant KRAS by HCT-8 cells. The full original blot is provided in the lower panel for context. Figure S6: Full western 
blot and densitometry data for analysis of downstream effects of KRAS transfer on p-ERK. Figure S7: Schematic visualizing the exchange of mutant KRAS between CRC cells through TNTs. Video S1: Time-lapse microscopy movie of FRAP-based mutant KRAS transport analyzed within a TNT. Video S2: Time-lapse microscopy movie of FRAP-based mutant KRAS transfer analyzed at the LOVO TNT and HCT-8 cell membrane interface. Video S3: Time-lapse microscopy movie of JF646 dyed HALO tagged KRAS moving within cellular protrusions. Video S4: Time-lapse microscopy movie of HCT-8 cell sharing GFP mutant KRAS protein via a TNT.

Author Contributions: Conceptualization, E.L., T.T., C.J.S., S.S.; methodology, S.D., P.W., T.T., D.C., M.S., C.C., K.M.-T., E.Z., T.K.S., D.N., S.S., E.L.; validation, S.D., P.W., D.C., M.S., C.C., E.Z.; formal analysis, S.D., P.W., T.T., T.K.S., D.N., C.J.S., S.S., E.L.; investigation, S.D., P.W., T.T., D.C., M.S., C.C., Y.R., K.M.-T., E.Z., T.K.S., D.N., S.S., E.L.; resources, T.T., K.M.-T., T.K.S., D.N., C.J.S., S.S., E.L.; data curation, S.D., P.W., E.L.; writing-original draft preparation, S.D. and E.L.; writing—review and editing, all authors; supervision, C.J.S., S.S., E.L.; project administration, E.L.; funding acquisition, E.L.

Funding: This research was supported with funding from the Department of Integrative Biology and Physiology, University of Minnesota (S.D.); Institutional Research Grant \#118198-IRG-58-001-52-IRG94 from the American Cancer Society (E.L.); the Mezin-Koats Colon Cancer Research Award (E.L.); The Randy Shaver Cancer Research and Community Fund (E.L.); the Litman Family Fund for Cancer Research, and donations from the Johnson family; cancer research fundraisers by the Mu Sigma Chapter of the Phi Gamma Delta Fraternity, University of Minnesota, and the Courage and a Cure Foundation, Goodyear, Arizona; Minnesota Medical Foundation/University of Minnesota Foundation (E.L.); a National Pancreas Foundation Research Grant (provided in partnership with the National Pancreas Foundation, several NPF Chapters and the Horvitz/Lebovitz Research Fund) (E.L.); Central Society for Clinical and Translational Research Early Career Development Award (E.L.); Minnesota Masonic Charities; the Masonic Cancer Center and Department of Medicine, Division of Hematology, Oncology and Transplantation, University of Minnesota (E.L.). This project was also funded in part with federal funds from the National Cancer Institute, NIH, under contract number HHSN261200800001E. The content of this publication does not necessarily reflect the views or policies of the Department of Health and Human Services, and the mention of trade names, commercial products, or organizations does not imply endorsement by the U.S.

Acknowledgments: The authors would like to thank Guillermo Marques, and Mark Sanders, for assistance with confocal microscopy performed at the University Imaging Centers at the University of Minnesota; Jason Motl, with assistance with FACS performed at the University of Minnesota Flow Cytometry Resource Center; Michael Franklin, for helpful suggestions and assistance in editing this manuscript; Katherine Ladner, for providing constructive critical review of the manuscript; and Blake Jacobsen for assistance with Western blot experiments. Special thanks to Joseph Metzger, John Osborn, and Stephen Katz, of the Department of Integrative Biology and Physiology at the University of Minnesota for their strong encouragement and helpful input throughout this project.

Conflicts of Interest: The authors declare no conflict of interest. The funders had no role in the design of the study; in the collection, analyses, or interpretation of data; in the writing of the manuscript, or in the decision to publish the results.

Financial Disclosures: E.L. discloses research collaborations and consulting for Novocure, LLC in 2018 and 2019, and grant funding 2019-2021; reimbursement for travel from GlaxoSmithKline, Inc. for giving a research presentation in 2016; consultation fees for Boston Scientific in 2019; unpaid consultation for Nomocan Pharmaceuticals; and membership on the Scientific Advisory Board for Minnetronix, LLC (unpaid). None of these sources funded, contributed to, or influenced research presented in this manuscript.

\section{References}

1. Fearon, E.R. Molecular genetics of colorectal cancer. Annu Rev. Pathol 2011, 6, 479-507. [CrossRef] [PubMed]

2. Makrodouli, E.; Oikonomou, E.; Koc, M.; Andera, L.; Sasazuki, T.; Shirasawa, S.; Pintzas, A. BRAF and RAS oncogenes regulate Rho GTPase pathways to mediate migration and invasion properties in human colon cancer cells: a comparative study. Mol. Cancer 2011, 10, 118. [CrossRef] [PubMed]

3. Wicki, A.; Herrmann, R.; Christofori, G. KRAS in metastatic colorectal cancer. Swiss Med. Wkly. 2010, 140, 13112. [CrossRef] [PubMed]

4. De Roock, W.; De Vriendt, V.; Normanno, N.; Ciardiello, F.; Tejpar, S. KRAS, BRAF, PIK3CA, and PTEN mutations: Implications for targeted therapies in metastatic colorectal cancer. Lancet Oncol. 2011, 12, 594-603. [CrossRef]

5. Grabocka, E.; Pylayeva-Gupta, Y.; Jones, M.J.; Lubkov, V.; Yemanaberhan, E.; Taylor, L.; Jeng, H.H.; Bar-Sagi, D. Wild-type $\mathrm{H}$ - and $\mathrm{N}$-Ras promote mutant K-Ras-driven tumorigenesis by modulating the DNA damage response. Cancer Cell 2014, 25, 243-256. [CrossRef] [PubMed]

6. Normanno, N.; Tejpar, S.; Morgillo, F.; De Luca, A.; Van Cutsem, E.; Ciardiello, F. Implications for KRAS status and EGFR-targeted therapies in metastatic CRC. Nat. Rev. Clin. Oncol. 2009, 6, 519-527. [CrossRef] 
7. Misale, S.; Yaeger, R.; Hobor, S.; Scala, E.; Janakiraman, M.; Liska, D.; Valtorta, E.; Schiavo, R.; Buscarino, M.; Siravegna, G.; et al. Emergence of KRAS mutations and acquired resistance to anti-EGFR therapy in colorectal cancer. Nature 2012, 486, 532-536. [CrossRef]

8. Baker, A.M.; Huang, W.; Wang, X.M.; Jansen, M.; Ma, X.J.; Kim, J.; Anderson, C.M.; Wu, X.; Pan, L.; Su, N.; et al. Robust RNA-based in situ mutation detection delineates colorectal cancer subclonal evolution. Nat. Commun 2017, 8, 1998. [CrossRef]

9. Rustom, A.; Saffrich, R.; Markovic, I.; Walther, P.; Gerdes, H.H. Nanotubular highways for intercellular organelle transport. Science 2004, 303, 1007-1010. [CrossRef]

10. Lou, E.; Fujisawa, S.; Morozov, A.; Barlas, A.; Romin, Y.; Dogan, Y.; Gholami, S.; Moreira, A.L.; Manova-Todorova, K.; Moore, M.A. Tunneling nanotubes provide a unique conduit for intercellular transfer of cellular contents in human malignant pleural mesothelioma. PLoS ONE 2012, 7, e33093. [CrossRef]

11. Thayanithy, V.; Dickson, E.L.; Steer, C.; Subramanian, S.; Lou, E. Tumor-stromal cross talk: Direct cell-to-cell transfer of oncogenic microRNAs via tunneling nanotubes. Transl Res. 2014, 164, 359-365. [CrossRef] [PubMed]

12. Demory Beckler, M.; Higginbotham, J.N.; Franklin, J.L.; Ham, A.J.; Halvey, P.J.; Imasuen, I.E.; Whitwell, C.; Li, M.; Liebler, D.C.; Coffey, R.J. Proteomic analysis of exosomes from mutant KRAS colon cancer cells identifies intercellular transfer of mutant KRAS. Mol. Cell Proteomics 2013, 12, 343-355. [CrossRef] [PubMed]

13. Lee, T.H.; Chennakrishnaiah, S.; Meehan, B.; Montermini, L.; Garnier, D.; D'Asti, E.; Hou, W.; Magnus, N.; Gayden, T.; Jabado, N.; et al. Barriers to horizontal cell transformation by extracellular vesicles containing oncogenic H-ras. Oncotarget 2016, 7, 51991-52002. [CrossRef] [PubMed]

14. Lee, T.H.; Chennakrishnaiah, S.; Audemard, E.; Montermini, L.; Meehan, B.; Rak, J. Oncogenic ras-driven cancer cell vesiculation leads to emission of double-stranded DNA capable of interacting with target cells. Biochem. Biophys. Res. Commun 2014, 451, 295-301. [CrossRef] [PubMed]

15. Rainy, N.; Chetrit, D.; Rouger, V.; Vernitsky, H.; Rechavi, O.; Marguet, D.; Goldstein, I.; Ehrlich, M.; Kloog, Y. H-Ras transfers from B to T cells via tunneling nanotubes. Cell Death Dis. 2013, 4, e726. [CrossRef] [PubMed]

16. Rechavi, O.; Goldstein, I.; Vernitsky, H.; Rotblat, B.; Kloog, Y. Intercellular transfer of oncogenic H-Ras at the immunological synapse. PLoS ONE 2007, 2, e1204. [CrossRef] [PubMed]

17. Phipps, A.I.; Buchanan, D.D.; Makar, K.W.; Win, A.K.; Baron, J.A.; Lindor, N.M.; Potter, J.D.; Newcomb, P.A. $K R A S$-mutation status in relation to colorectal cancer survival: The joint impact of correlated tumour markers. Br. J. Cancer 2013, 108, 1757-1764. [CrossRef] [PubMed]

18. Jo, P.; Konig, A.; Schirmer, M.; Kitz, J.; Conradi, L.C.; Azizian, A.; Bernhardt, M.; Wolff, H.A.; Grade, M.; Ghadimi, M.; et al. Heterogeneity of KRAS mutation status in rectal cancer. PLoS ONE 2016, 11, e0153278. [CrossRef] [PubMed]

19. Gerdes, H.H.; Carvalho, R.N. Intercellular transfer mediated by tunneling nanotubes. Curr. Opin. Cell Biol. 2008, 20, 470-475. [CrossRef] [PubMed]

20. Ady, J.W. Intercellular communication in malignant pleural mesothelioma: Properties of tunneling nanotubes. Front. Physiol 2014, 5, 400. [CrossRef] [PubMed]

21. Pasquier, J.; Guerrouahen, B.S.; Al Thawadi, H.; Ghiabi, P.; Maleki, M.; Abu-Kaoud, N.; Jacob, A.; Mirshahi, M.; Galas, L.; Rafii, S.; et al. Preferential transfer of mitochondria from endothelial to cancer cells through tunneling nanotubes modulates chemoresistance. J. Transl. Med. 2013, 11, 94. [CrossRef] [PubMed]

22. Wang, X.; Gerdes, H.H. Long-distance electrical coupling via tunneling nanotubes. Biochim. Biophys. Acta 2012, 1818, 2082-2086. [CrossRef] [PubMed]

23. Thayanithy, V.; Babatunde, V.; Dickson, E.L.; Wong, P.; Oh, S.; Ke, X.; Barlas, A.; Fujisawa, S.; Romin, Y.; Moreira, A.L.; et al. Tumor exosomes induce tunneling nanotubes in lipid raft-enriched regions of human mesothelioma cells. Exp. Cell Res. 2014, 323, 178-188. [CrossRef] [PubMed]

24. Desir, S.; Dickson, E.L.; Vogel, R.I.; Thayanithy, V.; Wong, P.; Teoh, D.; Geller, M.A.; Steer, C.J.; Subramanian, S.; Lou, E. Tunneling nanotube formation is stimulated by hypoxia in ovarian cancer cells. Oncotarget 2016, 7, 43150. [CrossRef]

25. Lou, E.; Gholami, S.; Romin, Y.; Thayanithy, V.; Fujisawa, S.; Desir, S.; Steer, C.J.; Subramanian, S.; Fong, Y.; Manova-Todorova, K.; et al. Imaging tunneling membrane tubes elucidates cell communication in tumors. Trends Cancer 2017, 3, 678-685. [CrossRef] [PubMed]

26. Camps, J.; Morales, C.; Prat, E.; Ribas, M.; Capella, G.; Egozcue, J.; Peinado, M.A.; Miro, R. Genetic evolution in colon cancer KM12 cells and metastatic derivates. Int. J. Cancer 2004, 110, 869-874. [CrossRef] [PubMed] 
27. Berg, K.C.G.; Eide, P.W.; Eilertsen, I.A.; Johannessen, B.; Bruun, J.; Danielsen, S.A.; Bjornslett, M.; Meza-Zepeda, L.A.; Eknaes, M.; Lind, G.E.; et al. Multi-omics of 34 colorectal cancer cell lines-A resource for biomedical studies. Mol. Cancer 2017, 16, 116. [CrossRef] [PubMed]

28. Sveen, A.; Bruun, J.; Eide, P.W.; Eilertsen, I.A.; Ramirez, L.; Murumagi, A.; Arjama, M.; Danielsen, S.A.; Kryeziu, K.; Elez, E.; et al. Colorectal cancer consensus molecular subtypes translated to preclinical models uncover potentially targetable cancer cell dependencies. Clin. Cancer Res. 2018, 24, 794-806. [CrossRef] [PubMed]

29. Ahmed, D.; Eide, P.W.; Eilertsen, I.A.; Danielsen, S.A.; Eknaes, M.; Hektoen, M.; Lind, G.E.; Lothe, R.A. Epigenetic and genetic features of 24 colon cancer cell lines. Oncogenesis 2013, 2, e71. [CrossRef]

30. Genther Williams, S.M.; Kuznicki, A.M.; Andrade, P.; Dolinski, B.M.; Elbi, C.; O'Hagan, R.C.; Toniatti, C. Treatment with the PARP inhibitor, niraparib, sensitizes colorectal cancer cell lines to irinotecan regardless of MSI/MSS status. Cancer Cell Int. 2015, 15, 14. [CrossRef]

31. Lao, V.V.; Welcsh, P.; Luo, Y.; Carter, K.T.; Dzieciatkowski, S.; Dintzis, S.; Meza, J.; Sarvetnick, N.E.; Monnat, R.J., Jr.; Loeb, L.A.; et al. Altered RECQ helicase expression in sporadic primary colorectal cancers. Transl. Oncol. 2013, 6, 458-469. [CrossRef] [PubMed]

32. Mouradov, D.; Sloggett, C.; Jorissen, R.N.; Love, C.G.; Li, S.; Burgess, A.W.; Arango, D.; Strausberg, R.L.; Buchanan, D.; Wormald, S.; et al. Colorectal cancer cell lines are representative models of the main molecular subtypes of primary cancer. Cancer Res. 2014, 74, 3238-3247. [CrossRef] [PubMed]

33. Sartore-Bianchi, A. Molecular markers beyond microsatellite instability for assessing prognosis in early-stage colorectal cancer: What happens at relapse? JAMA Oncol. 2017, 3, 481-482. [CrossRef] [PubMed]

34. Sinicrope, F.A.; Shi, Q.; Smyrk, T.C.; Thibodeau, S.N.; Dienstmann, R.; Guinney, J.; Bot, B.M.; Tejpar, S.; Delorenzi, M.; Goldberg, R.M.; et al. Molecular markers identify subtypes of stage III colon cancer associated with patient outcomes. Gastroenterology 2015, 148, 88-99. [CrossRef] [PubMed]

35. Wang, J.; Hu, K.; Guo, J.; Cheng, F.; Lv, J.; Jiang, W.; Lu, W.; Liu, J.; Pang, X.; Liu, M. Suppression of KRAS-mutant cancer through the combined inhibition of KRAS with PLK1 and ROCK. Nat. Commun. 2016, 7, 11363. [CrossRef] [PubMed]

36. Benvenuti, S.; Sartore-Bianchi, A.; Di Nicolantonio, F.; Zanon, C.; Moroni, M.; Veronese, S.; Siena, S.; Bardelli, A. Oncogenic activation of the RAS/RAF signaling pathway impairs the response of metastatic colorectal cancers to anti-epidermal growth factor receptor antibody therapies. Cancer Res. 2007, 67, 2643-2648. [CrossRef] [PubMed]

37. Goldstein, I.; Rainy, N.; Rechavi, O.; Kloog, Y. Intercellular transfer of Ras: Implications for immunity. Cell Cycle. 2013, 13, 7-8. [CrossRef] [PubMed]

38. Schiller, C.; Diakopoulos, K.N.; Rohwedder, I.; Kremmer, E.; von Toerne, C.; Ueffing, M.; Weidle, U.H.; Ohno, H.; Weiss, E.H. LST1 promotes the assembly of a molecular machinery responsible for tunneling nanotube formation. J. Cell Sci. 2013, 126, 767-777. [CrossRef] [PubMed]

39. Braeckmans, K.; Deschout, H.; Demeester, J.; De Smedt, S.C. Optical Fluoresence Microscopy: From the Spectral to the Nano Dimension; Measuring Molecular Dynamics; Springer Science \& Business Media: Berlin, Germany, 2011; pp. 153-163. [CrossRef]

40. Abubaker, J.; Bavi, P.; Al-Haqawi, W.; Sultana, M.; Al-Harbi, S.; Al-Sanea, N.; Abduljabbar, A.; Ashari, L.H.; Alhomoud, S.; Al-Dayel, F.; et al. Prognostic significance of alterations in KRAS isoforms KRAS-4A/4B and KRAS mutations in colorectal carcinoma. J. Pathol. 2009, 219, 435-445. [CrossRef] [PubMed]

41. Sun, M.; Graham, J.S.; Hegedus, B.; Marga, F.; Zhang, Y.; Forgacs, G.; Grandbois, M. Multiple membrane tethers probed by atomic force microscopy. Biophys. J. 2005, 89, 4320-4329. [CrossRef] [PubMed]

42. Sartori-Rupp, A.; Cordero Cervantes, D.; Pepe, A.; Gousset, K.; Delage, E.; Corroyer-Dulmont, S.; Schmitt, C.; Krijnse-Locker, J.; Zurzolo, C. Correlative cryo-electron microscopy reveals the structure of TNTs in neuronal cells. Nat. Commun. 2019, 10, 342. [CrossRef] [PubMed]

43. Van Haastert, P.J.; Keizer-Gunnink, I.; Kortholt, A. Coupled excitable Ras and F-actin activation mediates spontaneous pseudopod formation and directed cell movement. Mol. Biol. Cell 2017, 28, 922-934. [CrossRef] [PubMed]

44. Cushman-Vokoun, A.M.; Stover, D.G.; Zhao, Z.; Koehler, E.A.; Berlin, J.D.; Vnencak-Jones, C.L. Clinical utility of KRAS and BRAF mutations in a cohort of patients with colorectal neoplasms submitted for microsatellite instability testing. Clin. Colorectal Cancer 2013, 12, 168-178. [CrossRef] [PubMed] 
45. Oliveira, C.; Westra, J.L.; Arango, D.; Ollikainen, M.; Domingo, E.; Ferreira, A.; Velho, S.; Niessen, R.; Lagerstedt, K.; Alhopuro, P.; et al. Distinct patterns of KRAS mutations in colorectal carcinomas according to germline mismatch repair defects and hMLH1 methylation status. Hum. Mol. Genet. 2004, 13, 2303-2311. [CrossRef] [PubMed]

46. Zhang, X.; Ran, W.; Wu, J.; Li, H.; Liu, H.; Wang, L.; Xiao, Y.; Wang, X.; Li, Y.; Xing, X. Deficient mismatch repair and RAS mutation in colorectal carcinoma patients: A retrospective study in Eastern China. PeerJ 2018, 6, e4341. [CrossRef] [PubMed]

47. Le, D.T.; Uram, J.N.; Wang, H.; Bartlett, B.R.; Kemberling, H.; Eyring, A.D.; Skora, A.D.; Luber, B.S.; Azad, N.S.; Laheru, D.; et al. PD-1 blockade in tumors with mismatch-repair deficiency. N. Engl. J. Med. 2015, 372, 2509-2520. [CrossRef] [PubMed]

48. The Cancer Genome Atlas Network. Comprehensive molecular characterization of human colon and rectal cancer. Nature 2012, 487, 330-337. [CrossRef] [PubMed]

49. Armaghany, T.; Wilson, J.D.; Chu, Q.; Mills, G. Genetic alterations in colorectal cancer. Gastrointest Cancer Res. 2012, 5, 19-27.

50. Guinney, J.; Dienstmann, R.; Wang, X.; de Reynies, A.; Schlicker, A.; Soneson, C.; Marisa, L.; Roepman, P.; Nyamundanda, G.; Angelino, P.; et al. The consensus molecular subtypes of colorectal cancer. Nat. Med. 2015, 21, 1350-1356. [CrossRef]

51. Dubois, F.; Jean-Jacques, B.; Roberge, H.; Benard, M.; Galas, L.; Schapman, D.; Elie, N.; Goux, D.; Keller, M.; Maille, E.; et al. A role for RASSF1A in tunneling nanotube formation between cells through GEFH1/Rab11 pathway control. Cell Commun. Signal. 2018, 16, 66. [CrossRef]

52. Mendoza, M.C.; Er, E.E.; Blenis, J. The Ras-ERK and PI3K-mTOR pathways: Cross-talk and compensation. Trends. Biochem. Sci. 2011, 36, 320-328. [CrossRef] [PubMed]

53. Luhtala, N.; Hunter, T. Failure to detect functional transfer of active K-Ras protein from extracellular vesicles into recipient cells in culture. PLoS ONE 2018, 13, e0203290. [CrossRef] [PubMed]

54. Haigis, K.M.; Kendall, K.R.; Wang, Y.; Cheung, A.; Haigis, M.C.; Glickman, J.N.; Niwa-Kawakita, M.; Sweet-Cordero, A.; Sebolt-Leopold, J.; Shannon, K.M.; et al. Differential effects of oncogenic K-Ras and N-Ras on proliferation, differentiation and tumor progression in the colon. Nat. Genet. 2008, 40, 600-608. [CrossRef] [PubMed]

55. Mueller, S.; Engleitner, T.; Maresch, R.; Zukowska, M.; Lange, S.; Kaltenbacher, T.; Konukiewitz, B.; Ollinger, R.; Zwiebel, M.; Strong, A.; et al. Evolutionary routes and KRAS dosage define pancreatic cancer phenotypes. Nature 2018, 554, 62-68. [CrossRef] [PubMed]

56. Brownell, H.L.; Narsimhan, R.P.; Corbley, M.J.; Mann, V.M.; Whitfield, J.F.; Raptis, L. Ras is involved in gap junction closure in proliferating fibroblasts or preadipocytes but not in differentiated adipocytes. DNA Cell Biol. 1996, 15, 443-451. [CrossRef] [PubMed]

57. De Feijter, A.W.; Trosko, J.E.; Krizman, D.B.; Lebovitz, R.M.; Lieberman, M.W. Correlation of increased levels of Ha-ras T24 protein with extent of loss of gap junction function in rat liver epithelial cells. Mol. Carcinog 1992, 5, 205-212. [CrossRef]

58. El-Fouly, M.H.; Trosko, J.E.; Chang, C.C.; Warren, S.T. Potential role of the human Ha-ras oncogene in the inhibition of gap junctional intercellular communication. Mol. Carcinog 1989, 2, 131-135. [CrossRef]

59. Vanhamme, L.; Rolin, S.; Szpirer, C. Inhibition of gap-junctional intercellular communication between epithelial cells transformed by the activated H-ras-1 oncogene. Exp. Cell Res. 1989, 180, 297-301. [CrossRef]

60. Dias Carvalho, P.; Guimaraes, C.F.; Cardoso, A.P.; Mendonca, S.; Costa, A.M.; Oliveira, M.J.; Velho, S. KRAS oncogenic signaling extends beyond cancer cells to orchestrate the microenvironment. Cancer Res. 2018, 78, 7-14. [CrossRef]

61. Schmick, M.; Vartak, N.; Papke, B.; Kovacevic, M.; Truxius, D.C.; Rossmannek, L.; Bastiaens, P.I.H. KRAS localizes to the plasma membrane by spatial cycles of solubilization, trapping and vesicular transport. Cell 2014, 157, 459-471. [CrossRef]

62. Daubeuf, S.; Aucher, A.; Bordier, C.; Salles, A.; Serre, L.; Gaibelet, G.; Faye, J.C.; Favre, G.; Joly, E.; Hudrisier, D. Preferential transfer of certain plasma membrane proteins onto $\mathrm{T}$ and B cells by trogocytosis. PLoS ONE 2010, 5, e8716. [CrossRef] [PubMed]

63. Leibovitz, A.; Stinson, J.C.; McCombs, W.B., 3rd; McCoy, C.E.; Mazur, K.C.; Mabry, N.D. Classification of human colorectal adenocarcinoma cell lines. Cancer Res. 1976, 36, 4562-4569. [PubMed] 
64. Li, L.; Sarver, A.L.; Khatri, R.; Hajeri, P.B.; Kamenev, I.; French, A.J.; Thibodeau, S.N.; Steer, C.J.; Subramanian, S. Sequential expression of miR-182 and miR-503 cooperatively targets FBXW7, contributing to the malignant transformation of colon adenoma to adenocarcinoma. J. Pathol. 2014, 234, 488-501. [CrossRef] [PubMed]

65. Abounit, S.; Delage, E.; Zurzolo, C. Identification and characterization of tunneling nanotubes for intercellular trafficking. Curr. Protoc. Cell Biol. 2015, 67, 1-21. [CrossRef]

66. Ady, J. Tunneling nanotubes: An alternate route for propagation of the bystander effect following oncolytic viral infection. Mol. Ther. Oncolytics 2016, 3, 16029. [CrossRef] [PubMed]

67. Lou, E.; Fujisawa, S.; Barlas, A.; Romin, Y.; Manova-Todorova, K.; Moore, M.A.; Subramanian, S. Tunneling Nanotubes: A new paradigm for studying intercellular communication and therapeutics in cancer. Commun. Integr. Biol. 2012, 5, 399-403. [CrossRef] [PubMed]

68. Stephen, A.G.; Esposito, D.; Bagni, R.K.; McCormick, F. Dragging ras back in the ring. Cancer Cell 2014, 25, 272-281. [CrossRef] [PubMed]

69. Vallabhaneni, K.C.; Haller, H.; Dumler, I. Vascular smooth muscle cells initiate proliferation of mesenchymal stem cells by mitochondrial transfer via tunneling nanotubes. Stem Cells Dev. 2012, 21, 3104-3113. [CrossRef]

70. Bukoreshtliev, N.V.; Wang, X.; Hodneland, E.; Gurke, S.; Barroso, J.F.; Gerdes, H.H. Selective block of tunneling nanotube (TNT) formation inhibits intercellular organelle transfer between PC12 cells. FEBS Lett. 2009, 583, 1481-1488. [CrossRef]

(C) 2019 by the authors. Licensee MDPI, Basel, Switzerland. This article is an open access article distributed under the terms and conditions of the Creative Commons Attribution (CC BY) license (http://creativecommons.org/licenses/by/4.0/). 